\title{
Two Novel Kinases Phosphorylate Tau and the KSP Site of Heavy Neurofilament Subunits in High Stoichiometric Ratios
}

\author{
H. M. Roder and V. M. Ingram \\ Department of Biology, Massachusetts Institute of Technology, Cambridge, Massachusetts 02139
}

\begin{abstract}
We have identified, purified, and characterized two neurofilament/tau kinases from bovine brain, PK36 and PK40, with apparent $M_{r}$ of 36,000 and 40,000 and with novel biochemical properties. A specially designed immunoassay for phosphorylated epitopes in neurofilament (NF) proteins was used in the early stages of the purlflcation. Neither kinase is closely associated with the cytoskeleton. Both kinases phosphorylate bovine intermediate (NF-M) and heavy (NF-H) NF subunits and also bovine tau at the expected KSP sequences, though other sites cannot be ruled out. In human paired helical filaments, tau, phosphorylated at these same KSP sites, is a major characterized constituent. Neither kinase is activated by the usual second messengers. Tau and the above NF subunits are phosphorylated in high stoichiometric ratios. In the intermediate NF subunit, all the expected sites appear to be phosphorylated, but in the heavy NF subunit only $\mathbf{7}$ out of the $>\mathbf{4 0}$ expected sites can be phosphorylated by our kinases. We demonstrate that both kinases can induce considerable shifts of apparent $M_{r}$ with SDS-PAGE for tau and, for the first time in vitro, also for the intermediate NF subunit.

Interestingly, PK36 and particularly PK40 are strongly inhibited by an excess of free ATP. We propose that during normal aging, and in Alzheimer's disease, age-related mitochondrial dysfunction would reduce ATP levels, which in turn might release the neurofilament/tau kinase from inhibition with consequent paired helical filament formation.
\end{abstract}

Neurofilaments (NFs), the intermediate filaments specific for neurons, are an assembly of three subunits of apparent $M_{r}$ on SDS-PAGE of 68, 160, and $200 \mathrm{kDa}$, termed NF-L, NF-M and NF-H. All three subunits contain a highly conserved helical rod domain. The two heavier subunits also have extended C-terminal tail domains that are heavily phosphorylated. The cDNAderived sequences of the two heavy NF subunits have revealed the presence of 5, 12, and $>40$ Lys-Ser-Pro-(Val,Ala, $X$ ) repeats in the C-terminal domains of rat NF-M, human NF-M, and

\footnotetext{
Received Mar. 29, 1991; revised June 5, 1991; accepted June 6, 1991

This work was supported by the Baum Fund for Alzheimer's Research and, in part, by a fellowship from the Deutsche Forschungsgemeinschaft to H.M.R. Elisabeth Groginsky, an undergraduate student at MIT, participated in certain early experiments. We are grateful to Dr. K. S. Kosik, Harvard Medical School, Boston, for a gift of the mAb 5E2. We also acknowledge the gift of mAb RT97 from Dr. Brian Anderton, St. George's Hospital Medical School, London.

Correspondence should be addressed to Dr. V. M. Ingram, Room 56-601, Department of Biology, Massachusetts Insitute of Technology, Cambridge, MA 02139.

Copyright (C) 1991 Society for Neuroscience $0270-6474 / 91 / 113325-19 \$ 05.00 / 0$
}

human NF-H, respectively (Myers et al., 1987; Napolitano et al., 1987; Lees et al., 1988). These sequences very likely account for the majority of phosphorylation sites in NF-M and NF-H and also form the epitopes of several phosphoepitope-specific anti-NF monoclonal antibodies (mAbs) (Lee et al., 1988). The physiological significance of NFs and their phosphorylation is not very well understood yet (reviewed by Matus, 1988); correlative evidence suggests involvement in the regulation of axonal diameter (Hoffman et al., 1987; Pleasure et al., 1989). Electron microscopic studies in conjunction with antibody decoration (Hirokawa et al., 1984) and biochemical evidence (Minami and Sakai, 1983) favor NF-H as a component in interactions of the NF and microtubule networks. The phosphorylation status of NFs and their ability to promote tubulin polymerization are correlated in vitro (Minami and Sakai, 1985).

The existence of NF kinase(s) not activated by common second messengers and some of its expected properties were postulated from in vivo phosphorylation studies on extruded axoplasm of the giant axons of the squid (Pant et al., 1978, 1986) and of Myxicola (Shecket and Lasek, 1982). In vitro characterization of purified NF kinases has focused so far on activities that copurify with the NF cytoskeleton and can be dissociated under high salt conditions (Runge et al., 1981; Toru-Delbauffe and Pierre, 1983). There is currently no evidence of second messenger dependence of any of these activities. From a mixture of such kinases, one $67 \mathrm{kDa}$ activity has been purified to apparent homogeneity (Wible et al., 1989). This kinase prefers NF-H as a substrate, but only if not completely dephosphorylated. A cAMP-dependent kinase copurifying with microtubules has been shown to phosphorylate preferentially NF-M in NF triplets (Leterrier et al., 1981). In no case are the stoichiometry or the sites of phosphorylation known, and no shift of apparent $M_{r}$ of NF-M and NF-H on SDS-PAGE has been demonstrated. Such a shift is expected after incorporation of phosphate in high stoichiometric ratios into the dephosphorylated subunits. A smaller than expected gel shift associated with a heterogeneous state of KSP phosphorylation of NF-M is induced by uncharacterized kinases in mouse L-cells transfected with a human NF-M clone (Pleasure et al., 1990).

A possible pathological role of aberrant NF phosphorylation was considered when the anti-rat-NF mAb 07-5 (commercially available as SMI-34) was found to stain neurofibrillary tangles in brain tissue from Alzheimer's patients (Sternberger et al., 1985) but did not stain normal human brain tissue, except for cerebellar basket cell axons and certain motoneuron axons of patients $>60 \mathrm{yr}$ of age (Blanchard and Ingram, 1989). On the other hand, there is a report that the localization of the SMI34 epitope is exclusively perikaryonal, while most other mAbs 
reacting with NF phosphoepitopes stain axons preferentially (Sternberger and Sternberger, 1983).

However, immunochemical evidence (Grundke-Iqbal et al., 1986; Kosik et al., 1986; Wood et al., 1986; Nukina et al., 1987) concerning the cross-reactivities of a series of mAbs with NFs, microtubule-associated protein tau, and the main component of tangles and paired helical filaments (PHF) point to tau as a major constitucnt of PHFs. This deduction is reinforced by the isolation from PHFs of tau-derived peptides (Wischik et al., 1988), while no NF-derived peptides (Kondo et al., 1988) were obtained. A number of anti-NF mAbs cross-reacting with tau, among them SMI-31 and RT97, recognize the phosphorylated KSP sequence repeat in NF proteins (Lee et al., 1988) and may therefore also bind to one or both of the same phosphorylated sequences occurring in human and bovine tau (Goedert et al., 1989; Himmler et al., 1989). PHFs react strongly with RT97, but only after prolonged treatment with SDS, suggesting the presence of this phosphorylated epitope in PHF in a nonperipheral location (Rasool and Selkoe, 1984). Recently, a peptide derived from bovine tau carrying the epitope for the Alzheimer's disease (AD)-specific $\mathrm{mAb}$ Alz-50 has been shown to contain the C-terminal KSPV sequence that may be at least partially phosphorylated (Uéda et al., 1990). Several other lines of evidence indicate an abnormal levcl or an abnormal sitc of phosphorylation in the C-terminal portion of the tau molecule in AD (Grundke-Iqbal et al., 1986; Kondo et al., 1988; Iqbal et al., 1989). The fact that tau and NF share phosphoepitopes, very likely the KSPV sequence, suggests the possibility that kinases acting on the multiphosphorylation repeat (MPR) of NF proteins might also phosphorylate tau and contribute to its pathological involvement in PHF formation.

We describe here the purification, identification, and characterization of two kinases from bovine brain with novel biochemical properties, which became feasible with a specially designed immunoassay (Roder and Ingram, 1990). Neither kinase is closely associated with the cytoskeleton. Both activities phosphorylate tau and the MPR sequence of NF-M and NF-H, among other sites, in a second messenger-independent fashion and in high stoichiometric ratios. Moreover, we demonstrate shifts of apparcnt $M_{r}$ with SDS-PAGE for tau and, for the first time in vitro, also for NF-M.

\section{Materials and Methods}

Protein assays

Protein concentrations in column fractions were determined by a commercial Bradford assay (Pierce CB 250) with bovine serum albumin (BSA) as standard. Suspensions and solutions of purified NF were assayed with the BCA assay (Pierce Chemical Co., enhanced protocol, $60^{\circ} \mathrm{C}, 30 \mathrm{~min}$ ) and BSA as standard. The concentration of expressed human tau protein was determined by amino acid analysis.

\section{SDS-gel electrophoresis}

SDS-PAGE was carried out on $1.5-\mathrm{mm}$ gels as described previously (Laemmli, 1970). Acrylamide concentrations were $7.5 \%$ for NF proteins, $10 \%$ for tau proteins, and $12 \%$ for kinase fractions. Silver staining of gels was performed with the Bio-Rad kit based on the method of Merril et al. (1984).

\section{Nondenaturing gel electrophoresis}

Resolving gel, stacking gel, and buffers were as for SDS-PAGE, but SDS was omitted and $5 \mathrm{~mm} \mathrm{Mg}$-ATP and $1 \mathrm{~mm}$ dithiothreitol (DTT) were added; $7.5 \%$ gels were run at $4^{\circ} \mathrm{C}$. For preparative purposes, samples were loaded into 50-mm-wide slots. PK36 and PK40 bands after pre- parative runs were localized by loading test slices from a side strip in SDS sample buffer after 5 min of boiling and performing analytical SDS-PAGE.

\section{Western blots and dot blots}

Previously described methods (Towhin et al., 1979) were used for electrophoretic transfer of proteins from SDS gels to nitrocellulose $(0.22$ $\mu \mathrm{m}$; Schleicher and Schüll). Blots were blocked by $1 \mathrm{hr}$ incubation with $3 \%$ BSA in 10 mM PBS (pH 7.2) and washed once in $0.5 \%$ Triton $X-100$ and $10 \mathrm{~mm}$ PBS. Antibodies were diluted in sterile $10 \mathrm{~mm}$ PBS (pH 7.2 ), $0.5 \%$ Triton $\mathrm{X}-100$, and $10 \%$ fetal calf serum. Blots were incubated with SMI mAbs for at least $2 \mathrm{hr}$, with all other antibodies overnight. After incubations with antibodies blots were washed five times. Mouse mAbs were detected by reaction with horseradish peroxidase-linked goat anti-mouse antibody (Cappel) in 1:200 dilution and by staining with $0.05 \%$ 4-chloro-1-naphthol (Sigma) and $0.05 \% \mathrm{H}_{2} \mathrm{O}_{2}$ in $50 \mathrm{~mm}$ Tris-buffered saline (pH 7.5) and 33\% ethanol for 5-20 min. Rabbit polyclonal antibodies were detected by the Vectastain method (Vector Laboratories, Burlingame, CA): incubation for $1 \mathrm{hr}$ with 1:200 biotinconjugated goat anti-rabbit IgG diluted as above, followed by $1 \mathrm{hr}$ in 1:200 avidin/biotin-peroxidase reagent.

All incubations and washes were at room temperature. Incubations were sealed in plastic bags with $50 \mu 1$ of solution $/ \mathrm{cm}^{2}$ of membrane.

\section{Preparation of neurofilament triplet proteins}

The preparation of "native" NF triplet is a modification of previously described procedures (Tokutake et al., 1983; Lee et al., 1987). A freshly obtained bovine spinal cord (100-150 gm; $\Lambda$ rena and Sons, Hopkinton, MA) was desheathed, minced with a razor blade, and left for $2 \mathrm{hr}$ in 3 liters of $10 \mathrm{~mm}$ Tris (pH 7.0), $50 \mathrm{~mm} \mathrm{NaCl}, 2 \mathrm{~mm}$ EGTA, $1 \mathrm{~mm}$ DTT, and $0.1 \mathrm{~mm}$ phenylmethylsulfonyl fluoride (PMSF) at $4^{\circ} \mathrm{C}$ for swelling. The supernatant was decanted, and the swollen tissue was homogenized for $1 \mathrm{~min}$ in $200 \mathrm{ml}$ of a similar buffer containing $150 \mathrm{~mm} \mathrm{NaCl}$ (isotonic buffer) with an Ultra-Turax at $2 / 3$ speed. After 15 min centrifugation at $12,000 \times g$, the precipitate was twice rehomogenized in $200 \mathrm{ml}$ of isotonic buffer for $1 \mathrm{~min}$ at full speed. Supernatants of the centrifugations were combined and brought to $0.85 \mathrm{M}$ in sucrose by adding solid sucrose $(1 \mathrm{~mol} /$ liter). Centrifugation at $100,000 \times g$ for $4 \mathrm{hr}$ yielded about 200 mg of gelatinous precipitate, which was dissolved (aided by slow UltraTurax homogenization) in $100 \mathrm{ml}$ of adsorption buffer: $10 \mathrm{~mm}$ potassium phosphate $(\mathrm{pH} 7.4), 8 \mathrm{M}$ urea [deionized for $1-2 \mathrm{hr}$ over mixed-bed ion exchanger AG 501-X8 (D), Bio-Rad], and $0.5 \% \beta$-mercaptoethanol $(\beta-\mathrm{ME})$. NFs were adsorbed by shaking this solution for $10 \mathrm{~min}$ at $4^{\circ} \mathrm{C}$ with HTP (40 gm dry weight; Bio-Rad), preequilibrated in adsorption buffer. The adsorbent was sedimented for $10 \mathrm{~min}$ at 15,000 $\times g$ and washed $(10 \mathrm{~min}$ each) subsequently with $100 \mathrm{ml}$ of adsorption buffer, $3 \times 85 \mathrm{ml} 130 \mathrm{~mm} \mathrm{KPO}_{4}(\mathrm{pH} 7.0), 8 \mathrm{M}$ urea, and $0.5 \% \beta-\mathrm{ME}$, and once each with $50 \mathrm{ml} 300 \mathrm{~mm}$ and $250 \mathrm{mM} \mathrm{KPO}_{4}(\mathrm{pH} 7.0), 8 \mathrm{M}$ urea, and $0.5 \% \beta$-ME. The supernatants of the latter two washes contained the bulk amount of NF-L, NF-M, and NF-H and were combined for reconstitution of the NF triplet by dialysis into three changes of 1 liter of $10 \mathrm{~mm}$ morpholineethanesulfonic acid (MES; pH 6.8), $100 \mathrm{~mm}$ $\mathrm{NaCl}, 1 \mathrm{~mm} \mathrm{MgCl}$, and $1 \mathrm{mM}$ EGTA. After $30 \mathrm{~min}$ of incubation at $37^{\circ} \mathrm{C}$ and centrifugation for $6 \mathrm{hr}$ at $120,000 \times g, 40-60 \mathrm{mg}$ of NF triplet proteins were obtained. The gelatinous precipitate was rehomogenized in $40 \%$ glyccrol with a glass-Teflon homogenizer to form suspensions of $2.5-3 \mathrm{mg} / \mathrm{ml}$ and stored at $-20^{\circ} \mathrm{C}$.

In a similar way, the so-called "reconstituted" NF triplet was reconstituted from the three purified subunits (see below) after recombination of the appropriate DEAE column fractions.

We have observed a striking difference in the behavior of native and dephosphorylated native NF triplet during prolonged storage in glycerolcontaining solutions at $-20^{\circ} \mathrm{C}$. Both preparations can be homogenized to form finely dispersed suspensions initially. Native NF triplet suspensions can be stored for at least $2 \mathrm{yr}$ without apparent physical change, while the dephosphorylated native NF triplet will not resuspend after several weeks. This change is reflected by a much lower susceptibility of NF-H in stored dephosphorylated native NF triplet preparations to

\footnotetext{
We used two preparations of NF triplet protein-one, called "native" NF triplet, was obtained by batch hydroxyapatite (HTP) chromatography and removing the urea used by dialysis; the other preparation was the "reconstituted" NF triplet, obtained from fast protein liquid chromatography (FPLC)-purified NF subunits, again removing urea by dialysis.
} 
phosphorylation by our kinase(s) compared to a fresh preparation (not shown).

\section{Separation of individual NF subunits}

For separation of the individual NF subunits, a previously described procedure (Tokutake, 1984) was modified. The reconstituted NF triplet precipitate was taken up $(0.5-1 \mathrm{ml} / \mathrm{mg}$ NF protein) in $10 \mathrm{~mm}$ sodium phosphate (pH 6.8), $6 \mathrm{M}$ urea, and $0.5 \% \beta$-ME (starting buffer), centrifuged at $100,000 \times g$ for $1 \mathrm{hr}$, and loaded onto a $40 \times 1.5 \mathrm{~cm}$ DEAESephacel column (Pharmacia). NF subunits were eluted at room temperature with $600 \mathrm{ml}$ of a linear gradient formed by starting buffer and $400 \mathrm{~mm}$ sodium phosphate $(\mathrm{pH} 6.8), 6 \mathrm{M}$ urea, and $0.5 \% \beta$-ME at $10-$ $15 \mathrm{ml} / \mathrm{hr}$. Fractions were collected (120 fractions, $5 \mathrm{ml}$ each), and fractions $41-48,71-80$, and $85-94$ were pooled; these contained pure NF$\mathrm{H}, \mathrm{NF}-\mathrm{M}$, and NF-L according to anaysis by SDS-PAGE. The three fractions were concentrated to $2-3 \mathrm{ml}$ by vacuum dialysis and dialyzed into water. NF-L was obtained as a clear gelatinous precipitate after centrifugation for $1 \mathrm{hr}$ at $100,000 \times g$; NF-M and NF-H were precipitated by ammonium sulfate. For storage at $-20^{\circ} \mathrm{C}$, the pure subunits were homogenized (NF-L) or dissolved (NF-M, NF-H) in $40 \%$ glycerol to form stock concentrations of about $1 \mathrm{mg} / \mathrm{ml}$ of protein.

NF subunits were also separated by FPLC on a Mono-Q $5 / 5$ column (Karlsson et al., 1987).

\section{Dephosphorylation of the NF triplet}

Typically, $1 \mathrm{ml}$ (2.5-3 $\mathrm{mg})$ of NF triplet stock solution was incubated for $5 \mathrm{~d}$ at $37^{\circ} \mathrm{C}$ with $10 \mathrm{U}$ (about $400 \mu \mathrm{g}$ ) of Escherichia coli alkaline phosphatase (type III-N) in a total volume of $2 \mathrm{ml}$ containing $50 \mathrm{~mm}$ Tris (pH 8.5), $100 \mathrm{~mm} \mathrm{NaCl}, 0.5 \mathrm{~mm} \mathrm{MgSO}_{4}, 0.5 \mathrm{~mm} \mathrm{ZnSO}_{4}, 1 \mathrm{~mm}$ PMSF, and $5 \mu \mathrm{g}$ of leupeptin. The NF triplet protein was scparated from the phosphatase by centrifugation for $1 \mathrm{hr}$ at $100,000 \times \mathrm{g}, 4^{\circ} \mathrm{C}$. The pellet was washed twice by rehomogenization in $2 \mathrm{ml}$ of water. The final pellet (yield, 40-50\%) was resuspended by a glass-Teflon homogenizer in $40 \%$ glycerol to form a stock solution of about $0.5 \mathrm{mg} / \mathrm{ml}$, stored at $-20^{\circ} \mathrm{C}$. Dephosphorylated NF triplet tended to aggregate over several weeks of storage.

After analytical SDS-PAGE of dephosphorylation reactions, phosphatase and accompanying impurities were removed by subjecting the gel for $6 \mathrm{hr}$ to a "Western blot electrophoresis" in an SDS-free buffer prior to staining. Under those conditions very little of the NF proteins was lost.

\section{Dephosphorylation of subunits NF-M and NF-H}

NF-M $(0.5 \mathrm{gm})$ was dephosphorylated by incubation with $2 \mathrm{U}(80 \mu \mathrm{g})$ of $E$. coli alkaline phosphatase for $5 \mathrm{~d}$ in a total volume of $1 \mathrm{ml}$ under the same buffer conditions as used for the NF triplet. The phosphatase was removed by gel filtration of the mixture on a $50 \times 1.5 \mathrm{~cm}$ Sephadex G200 column (50-120 $\mu \mathrm{m}, 10 \mathrm{ml} / \mathrm{hr}$ flow rate), equilibrated with 10 $\mathrm{mm}$ Bis-Tris (pH 7.0) and $100 \mathrm{~mm} \mathrm{NaCl}$. Fractions were analyzed by SDS-PAGE. NF-M-containing fractions around the exclusion volume were pooled $(4 \mathrm{ml})$, dialyzed into water, concentrated in a SpeedVac, and stored at $-20^{\circ} \mathrm{C}$ as a $0.3 \mathrm{mg} / \mathrm{ml}$ stock solution containing $40 \%$ glycerol. The yield was $270 \mu \mathrm{g}(54 \%)$.

NF-H $(1.05 \mathrm{mg})$ was dephosphorylated by incubation with $120 \mu \mathrm{g}$ of calf intestinal alkaline phosphatase for $6 \mathrm{~d}$ at $37^{\circ} \mathrm{C}$ in a total volume of

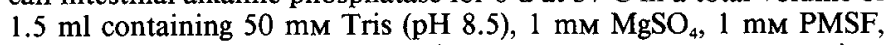
and $15 \mu \mathrm{g}$ of leupeptin. Separation from the phosphatase, concentration, and storage were as described for NF-M. The yield was $700 \mu \mathrm{g}(67 \%)$.

The dephosphorylation reactions for both NF subunits were monilored by spotting 1-1.5 $\mu \mathrm{g}$ of NF protein on nitrocellulose. Blocking, staining with SMI-31 and SMI-34, and development of the blots were performed as described for Western blots (see above).

\section{Immunodot blot assays of kinases}

Assays were performed in $50 \mathrm{mM}$ HEPES (pH 7.0), $2 \mathrm{mM} \mathrm{MgCl}_{2}, 1 \mathrm{~mm}$ ATP, and 2 mM DTT in a total volume of $30 \mu \mathrm{l}$ with $5 \mu \mathrm{g}$ of dephosphorylated native NF triplet or $1.2 \mu \mathrm{g}$ of dephosphorylated pure subunits NF-M or NF-H as substrates together with a control assay lacking NFs. After incubation at $37^{\circ} \mathrm{C}$ for $18 \mathrm{hr}$, assays were diluted to $100 \mu \mathrm{l}$ with $10 \mathrm{~mm}$ PBS ( $\mathrm{pH} 7.2$ ), and aliquots of $50 \mu \mathrm{l}$ were spotted on nitrocellulose. Further processing was carried out as described for Western and dot blots (see above).

\section{${ }^{32} \mathrm{P}$ assays of tau/NF kinases}

Radioactive assays in the same buffer system as for immunoassays contained $5 \mu \mathrm{g}$ of HTP-purified native NF triplet as substrate $(3 \mu \mathrm{g}$ of substrate proteins other than NFs) and $150-250 \mathrm{cpm} / \mathrm{pmol} \gamma^{-32} \mathrm{P}-\mathrm{ATP}$. Incubation times were $15 \mathrm{~min}$ at $37^{\circ} \mathrm{C}$ for activities up to about $1 \mathrm{pmol}$ min/assay, since the assay responses were linear within these time intervals. Assays were stopped by cooling on ice, addition of $20 \mu \mathrm{l}$ of 25 mM EDTA, and immediate transfer of the mixture onto glass filters (Whatman GF/A) wetted with $10 \%$ trichloroacetic acid (TCA) and $2 \%$ sodium pyrophosphate (PPA). The glass filters were washed twice for $1 \mathrm{hr}$ and once for at least $3 \mathrm{hr}$ in 10\% TCA and 2\% PPA and finally in ethanol and were air dried. Radioactivity was assessed by scintillation counting (Beckman LS 230) with $5 \mathrm{ml}$ of "Liquiscint" (National Diagnostics) for $20 \mathrm{~min}$. Assays were routinely carried out in triplicate except for some duplicate assays in a few explicitly mentioned cases; a control assay lacking NFs was subtracted from the mean value.

Assays to be analyzed with SDS-PAGE were stopped with an equivalent amount of sample buffer, boiled for $3 \mathrm{~min}$, and run on $7.5 \%$ gels. After staining with Coomassie blue, destaining, and drying on Whatman 3MM paper, autoradiography was performed with a Du Pont Cronex screen intensifier at $-70^{\circ} \mathrm{C}$. For quantitative measurements, radioactive bands of individual NF subunits were cut out and placed in an Eppendorf vial immersed in $20 \mathrm{ml}$ of water, and the Cerenkov radiation of the sample was counted. Counting efficiency was about $30 \%$.

\section{Phosphorylations with $\mathrm{Ca}^{2+} /$ calmodulin-dependent kinase II and protein kinase $C$}

Incubation conditions were at $37^{\circ} \mathrm{C}$ in $30 \mu \mathrm{l}$ of $50 \mathrm{~mm}$ HEPES (pH 7.5), $10 \mathrm{mM} \mathrm{Mg}^{2+}, 5 \mathrm{mM} \mathrm{Ca}^{2+}, 1 \mathrm{~mm}$ EGTA, $2 \mathrm{~mm}$ DTT, $1 \mathrm{~mm} \mathrm{ATP}$, and $50 \mu \mathrm{g} / \mu \mathrm{l}$ calmodulin and phosphatidylserine, respectively, and $5 \mu \mathrm{g}$ of NF triplet protein.

\section{Purification of the NF/tau kinases}

\section{Step I}

A fresh bovine brain ( $350-450 \mathrm{gm}$ wet weight) was cleaned from meninges and blood vessels and homogenized at $4^{\circ} \mathrm{C}$ in $350 \mathrm{ml}$ of homogenization buffer ( $10 \mathrm{~mm}$ Bis-Tris, pH $7.0,150 \mathrm{~mm} \mathrm{NaCl}, 2 \mathrm{~mm}$ EGTA, 1 mM DTT, $0.1 \mathrm{~mm}$ PMSF, $5 \mu \mathrm{g} / \mathrm{ml}$ leupeptin) with an UltraTurax or a Sorvall Omni-Mixer for $3 \mathrm{~min}$. The pellet of the centrifugation at $20,000 \times g$ for $20 \mathrm{~min}$ was extracted twice, each with $300 \mathrm{ml}$ of homogenization buffer. The turbid supernatants were clarified by centrifugation at $100,000 \times g$ for $4 \mathrm{hr}$. Solid ammonium sulfate (AS) was added slowly over about $4 \mathrm{hr}$ while keeping the $\mathrm{pH}$ at $8.0-8.5$ with ammonia. The precipitate obtained between $35 \%$ and $45 \%$ saturation was collected by centrifugation at $20,000 \times g$ for $20 \mathrm{~min}$, redissolved in $20 \mathrm{ml}$ of $10 \mathrm{~mm}$ HEPES ( $\mathrm{pH} 7.0$ ), $1 \mathrm{~mm} \mathrm{MgCl}_{2}, 1 \mathrm{~mm}$ EGTA, and 1 mM DTT, and dialyzed extensively against this buffer to form a "crude enzyme" stock solution of about $20 \mathrm{mg} / \mathrm{ml}$ protein, which could be stored for several weeks at $4^{\circ} \mathrm{C}$ with little loss of activity.

\section{Step II}

$20 \mathrm{ml}$ of crude enzyme were dialyzed into CM-Sepharose starting buffer (5 mM magnesium acetate, $5 \mathrm{~mm}$ ATP, $1 \mathrm{~mm}$ DTT, $10 \%$ glycerol, $0.02 \%$ sodium azide, adjusted to $\mathrm{pH} 6.0$ with Bis-Tris) and loaded onto a $3 \times$ $2.5 \mathrm{~cm}$ CM-Sepharose column equilibrated with starting buffer. The column was washed with $60 \mathrm{ml}$ of starting buffer at about $50 \mathrm{ml} / \mathrm{hr}$, and then the kinases were eluted in one step with $85 \mathrm{~mm}$ magnesium acetate, $5 \mathrm{~mm}$ ATP, $1 \mathrm{~mm}$ DTT, $10 \%$ glycerol, and $0.02 \%$ sodium azide (pH 6.0), as a fraction of $15 \mathrm{ml}$ volume.

\section{Step III}

The combined fractions of the CM-Sepharose chromatography containing the bulk of the activity were dialyzed into fivefold-diluted gel filtration buffer ( $48 \mathrm{~mm}$ Bis-Tris, pH 7.0, $5 \mathrm{~mm} \mathrm{MgCl}_{2}, 5 \mathrm{mM} \mathrm{ATP,} 1$ mM DTT, $0.02 \%$ sodium azide), concentrated to about $3 \mathrm{ml}$ in a SpeedVac, and loaded onto a $95 \times 2.5 \mathrm{~cm}$ column of Sephadex G200 Superfine (Pharmacia). After elution of $155 \mathrm{ml}$ at a flow rate of 1.5-2 $\mathrm{ml} / \mathrm{hr}$, fractions of $5 \mathrm{ml}$ were collected. No significant contaminating phosphatase activity could be detected at this stage in the fractions containing PK36 and PK40 (see below). 


\section{Step IV}

Method $A$. Gel filtration fractions containing significant amounts of PK40 (fractions 17-19) and PK 36 (fractions 21-22), according to SDSPAGE analysis, were pooled, dialyzed into Mono-Q starting buffer (20 mM Tris, pH 8.0, $20 \mathrm{~mm} \mathrm{MgCl}_{2}, 5 \mathrm{~mm}$ ATP, $1 \mathrm{~mm}$ DTT, $0.02 \%$ sodium azide), and loaded on an HR 5/5 Mono-Q FPLC column (Pharmacia) equilibrated with starting buffer. Elution of PK40 at a flow rate of $1 \mathrm{ml} /$ min started with $5 \mathrm{ml}$ of starting buffer followed by a linear gradient of $7 \mathrm{ml}$ up to $65 \mathrm{~mm} \mathrm{MgCl}, 7 \mathrm{ml}$ isocratic elution at $65 \mathrm{~mm} \mathrm{MgCl}_{2}$, and finally a linear gradient up to $110 \mathrm{mM} \mathrm{MgCl}_{2}$ formed with elution buffer (20 mM Tris, pH 8.0, $110 \mathrm{~mm} \mathrm{MgCl}_{2}, 5 \mathrm{~mm}$ ATP, $1 \mathrm{~mm}$ DTT, $0.02 \%$ sodium azide). The gradient profile for PK36 was similar, except that the isocratic step was at $60 \mathrm{mM} \mathrm{MgCl}$. Peak fractions of the NF kinases (PK40, fractions 11-12; PK36, fractions 12-13) were pooled, dialyzed into storage buffer ( $20 \mathrm{~mm}$ Bis-Tris, $\mathrm{pH} 7.0,2 \mathrm{~mm} \mathrm{MgCl}_{2}, 2 \mathrm{~mm}$ ATP, $1 \mathrm{mM}$ DTT, $0.02 \%$ sodium azide), and concentrated about 10 -fold in microconcentrators (Amicon 10) for storage purposes. The enzyme is stable in the Mg-ATP-containing storage buffer. Activity was retained for several days at $4^{\circ} \mathrm{C}$ and after five cycles of freeze-thawing with little loss.

Method B. All gel filtration fractions containing SMI epitope reconstituting activity (fractions 14-23) were pooled, and PK 40 was separated from PK 36 by Mono-Q FPLC with a gradient profile similar to method A for PK40. Fractions 9-10 and 11-12 contained almost exclusively PK36 and PK40, respectively, although in much lower purity than in method A.

\section{Step $V$}

Elution of kinase activity from gel slices. The purity of PK40 was substantially improved by preparative gel electrophoresis. For detection of PK36 and PK40 activity, gel slices were left overnight in $30 \mu \mathrm{l}$ of 20 mM Bis-Tris (pH 7.0), $2 \mathrm{~mm} \mathrm{Mg-ATP,} \mathrm{and} 1 \mathrm{~mm} \mathrm{DTT}$; aliquots of supernatants were used in standard ${ }^{32} P$ and immunoassays. PK40 was eluted preparatively from gel slices of a $7.5 \%$ polyacrylamide gel in an electroeluter (model UEA, International Biotechnologies, New Haven, $\mathrm{CI}$ ) in two consecutive $30 \mathrm{~min}$ runs at $120 \mathrm{~V}$ and $4^{\circ} \mathrm{C}$ into a trapping buffer consisting of $7.5 \mathrm{~m}$ ammonium acetate, $10 \mathrm{~mm} \mathrm{Mg-ATP,} 2 \mathrm{~mm}$ DTT, and a trace of bromophenol blue. The elution buffer contained $25 \mathrm{~mm}$ Tris (pH 8.3), $192 \mathrm{~mm}$ glycine, $2 \mathrm{~mm} \mathrm{Mg-ATP}$, and $1 \mathrm{~mm}$ DTT. The kinase was dialyzed into a storage buffer of $20 \mathrm{~mm}$ Bis-Tris $(\mathrm{pH}$ 7.0), $2 \mathrm{~mm} \mathrm{Mg-ATP}$, and $1 \mathrm{~mm}$ DTT and concentrated about 10-fold in a microconcentrator (Amicon 10).

A relatively pure mix of PK $36 / 40$, as used for the identification of the 36,000 and 40,000 proteins as kinases, was obtainerl after pooling of gel filtration fractions 16-23 and elution from Mono-Q with an uninterrupted linear gradient of $17 \mathrm{ml}$ from 20 to $110 \mathrm{mM} \mathrm{MgCl}_{2}$.

An uncharacterized and labile activity not due to PK40 or PK 36 was found in the trailing fractions $23-25$ of the gel filtration. Elution from Mono-Q with a gradient profile as used for PK 36 (method A) occurred in fractions 11-12 (PK36, fractions 12-13) with $>90 \%$ loss of activity. No band could be assigned on a silver-stained SDS polyacrylamide gel electrophoresis, and no 36 or $40 \mathrm{kDa}$ band was found.

High salt extraction of the brain cytoskeletal fraction. The pellet of the $100,000 \times g$ centrifugation of the whole-brain homogenate was resuspended in $70 \mathrm{ml}$ of $20 \mathrm{~mm}$ PBS, $0.8 \mathrm{M} \mathrm{KCl}, 10 \mathrm{mM} \mathrm{MgCl}, 2 \mathrm{~mm}$ EGTA, $1 \mathrm{~mm}$ EDTA, and $0.5 \% \beta$-mercaptoethanol, pH 7.0 (ToruDelbauffe and Pierre, 1983), and stirred for $4 \mathrm{hr}$ at $4^{\circ} \mathrm{C}$. After $1 \mathrm{hr}$ centrifugation at $100,000 \times \mathrm{g}$, the pellet was recxtracted with $70 \mathrm{ml}$ of fresh high-salt buffer for another $4 \mathrm{hr}$. The combined supernatants were subjected to ammonium sulfate fractionation as described for the wholebrain supernatant (see above). Precipitates were collected by centrifugation at $27,000 \times g$ for $15 \mathrm{~min}$, redissolved in $2 \mathrm{ml}$ each of $100 \mathrm{~mm}$ MES, $2 \mathrm{~mm} \mathrm{MgCl}_{2}, 1 \mathrm{~mm}$ EGTA, and $0.5 \% \beta$-mercaptoethanol (pH 6.5 ), and dialyzed into this buffer.

\section{Phosphatase assays}

${ }^{32} \mathrm{P}$-labeled NF triplet was prepared by incubation of $465 \mu \mathrm{g}$ of dephosphorylated NF triplet under standard assay conditions (see above) with 14 units ( 1 unit $=1 \mathrm{pmol}$ of ${ }^{32} \mathrm{P}-\mathrm{PO}_{4}$ transferred $/ \mathrm{min}$ ) of $\mathrm{NF}$ kinase I activity and $275 \mathrm{cpm} / \mathrm{pmol} \gamma-{ }^{32} \mathrm{P}-\mathrm{ATP}$. After $18 \mathrm{hr}$ at $37^{\circ} \mathrm{C}$, the mixture was diluted to $1.2 \mathrm{ml}$ with water and the NF triplet was recovered by centrifugation for $1 \mathrm{hr}$ at $100,000 \times \mathrm{g}$. The pellet was rehomogenized twice in $1 \mathrm{ml}$ of water and resedimented to remove excess ATP as monitored by scintillation counting of the wash supernatants. The final pellet containing $2000 \mathrm{cpm} / \mu \mathrm{g}$ of protein was homogenized in $80 \mu \mathrm{l}$ of $40 \%$ glycerol and stored at $-20^{\circ} \mathrm{C}$.

To assay for contaminating phosphatase activity in the two kinase peaks of step III, $5.6 \mu \mathrm{g}$ of ${ }^{32} \mathrm{P}$-NF triplet were incubated at $37^{\circ} \mathrm{C}$ with amounts of the two fractions as used in NF kinase assays under standard conditions (see above) for $15 \mathrm{~min}$ and for $18 \mathrm{hr}$. Identical control assays were performed without kinase fractions. Each assay was mixed with $20 \mu \mathrm{l}$ of $1 \%$ BSA solution and $120 \mu \mathrm{l}$ of $10 \%$ TCA, left for $15 \mathrm{~min}$ at room temperature, and centrifuged at $12,000 \times g$ for $5 \mathrm{~min}$. Aliquots $(100 \mu \mathrm{l})$ of each supernatant were scintillation counted.

\section{Preparation of tau protein}

Tau protein was isolated in the course of the kinase purification procedure as a by-product from gel filtration fractions preceding the fractions containing activity. The bulk of tau eluted as a very broad peak in fractions $1-12$, as detected by immunodot blotting with the mAb 5E2 (Kosik et al., 1986). From the pooled fractions, tau was obtained after $\mathrm{HClO}_{4}$ treatment and AS fractionation of the supernatant as described (Uéda et al., 1990). Two tau fractions were obtained by subsequent FPLC on Mono-S with a linear gradient of $0-200 \mathrm{~mm} \mathrm{NaCl}$, 20 mM HEPES (pH 6.9), 1 mM EDTA, and 1 mM DTT (Hagestedt et al., 1989), which were distinguished only by the relative amounts of the three major isoforms resolved by SDS-PAGE. Fraction tau I $(0.48 \mathrm{mg})$ was obtained from the flow-through fraction; fraction tau II $(0.90 \mathrm{mg})$ eluted as a broad peak between 50 and $150 \mathrm{~mm} \mathrm{NaCl}$.

\section{Dephosphorylation of tau protein}

Tau I and tau II (165 $\mu \mathrm{g}$ total of a 1:2 mix) were incubated overnight with $4.8 \mu \mathrm{g}$ of $E$. coli alkaline phosphatase and $6.5 \mu \mathrm{g}$ of calf intestinal phosphatase in $0.2 \mathrm{ml} 50 \mathrm{~mm}$ Tris (pH 8.5), $0.5 \mathrm{mM} \mathrm{MgSO}_{4}, 0.5 \mathrm{~mm}$ $\mathrm{ZnSO}_{4}$, and $0.5 \mathrm{~mm} \mathrm{PMSF}$ at $37^{\circ} \mathrm{C}$. The phosphatases were quantitatively removed by precipitation with $6 \mu \mathrm{l}$ of $70 \% \mathrm{HClO}_{4}$ and centrifugation for $15 \mathrm{~min}$ at $12,000 \times \mathrm{g}$; a considerable amount of the tau I and tau II proteins also precipitated in this step. Dephosphorylated tau I and tau II $(25 \mu \mathrm{g})$ were recovered from the supernatant after neutralization and dialysis into water.

\section{Materials}

E. coli alkaline phosphatase type III-N, histone type III-S (calf thymus, lysine-rich fraction), dephosphorylated $\alpha$-casein (bovine), phosvitin (egg yolk), calmodulin from bovine brain, synthetic Walsh inhibitor (rabbit), cAMP and cGMP (sodium salts), adenosine 5'-triphosphate highest purity (sodium salt), and guanosine 5 -triphosphate (lithium salt) were purchascd from Sigma Chemicals. Calf intestinal alkaline phosphatase (special molecular biology grade) was obtained from Boehringer Mannheim Biochemicals. $\gamma-{ }^{32} \mathrm{P}-\mathrm{ATP}(3000 \mathrm{Ci} / \mathrm{mmol})$ and $\gamma-{ }^{32} \mathrm{P}-\mathrm{GTP}$ were from Du Pont-New England Nuclear. The monoclonal mouse anti-ratNF antibodies SMI-31, SMI-33, and SMI-34 were from SternbergerMeyer Immunochemicals, Jarretsville, MD, and polyclonal anti-tubulin was from ICN. Twice-cycled microtubules and purified tubulin from calf brain were a gift of Dr. F. Solomon (Department of Biology, MIT). $\mathrm{L}-\alpha$-Phosphatidylserine and samples of protein kinase $\mathrm{C}$ and calcium/ calmodulin-dependent kinase II were kindly provided by Dr. A. C. Nairn (Rockefeller University). Human tau protein expressed in E. coli from the clone htau 40 was generously provided by Dr. E.-M. Mandelkow (Max Planck Research Unit for Structural Molecular Biology, Hamburg).

\section{Results}

Preparation of dephosphorylated NF proteins for kinase immunoassays

We had to prepare NF proteins completely devoid of immunoreactivity with mAbs SMI-31 and SMI-34 in order to use an assay for kinase activity specific for these epitopes, the repeated KSP sequences (multiphosphorylation repeat [MPR]). This specificity was necessary because crude brain extracts are expected to contain a very large number of protein kinases. The 
epitope of SMI-31 had been shown earlier to be the phosphorylated MPR sequence (Lee et al., 1988), while the SMI-34 phosphoepitope remained undefined. Such a preparation of dephosphorylated NF proteins would, however, be strongly reactive with the mAb SMI-33, which is specific for the nonphosphorylated KSP sequence (Lee et al., 1988).

\section{Successful dephosphorylation of NF triplet depends on its method of preparation}

We used two preparations of NF triplet protein-one, called native NF triplet, was obtained by batch HTP chromatography and removing the urea used by dialysis; the other preparation was the reconstituted NF triplet, obtained from FPLC-purified NF subunits, again removing urea by dialysis.

Dephosphorylation of native NF triplet with $E$. coli alkaline phosphatase reportedly removes $>90 \%$ of all phosphate groups in NF-M and NF-H (Carden et al., 1985). In our experiments, the shift of apparent $M_{r}$ on SDS-PAGE accompanying dephosphorylation of NF-M and NF-H in the triplet proceeded very quickly and was virtually completed within minutes (Fig. 1 , lanes B). However, $5 \mathrm{~d}$ of incubation were necessary to abolish completely the SMI-31 and SMI-34 immunoreactivity (data not shown). Before analysis, the phosphatase was removed quantitatively by repeated sedimentation of the dephosphorylated triplet.

Surprisingly, the NF-M and NF-H subunits in the NF triplet that had been reconstituted from FPLC-purified subunits reacted very much more slowly as monitored by gel shift, removal of SMI-31 reactivity, and generation of the SMI-33 epitope (Fig. 1 , lanes $C$ ). Loss of SMI-31 reactivity was not complete even after $5 \mathrm{~d}$ of incubation.

The reason for this differential behavior of native and reconstituted NF triplet remains unclear. Tubulin was detected as a minor impurity in the readily reacting triplet preparation by Western blotting, but addition of tubulin or crude microtubules to the FPLC-purified NF triplet did not affect the dephosphorylation reaction.

\section{Different phosphatases are required for dephosphorylation of purified $N F-M$ and $N F-H$}

FPLC-purified NF-M but not FPLC-purified NF-H could be satisfactorily dephosphorylated with $E$. coli alkaline phosphatase so as to be unreactive to SMI-31 and SMI-34 under conditions similar to those used for the NF triplet. The shift of apparent $M_{r}$ on SDS-PAGE and the removal of SMI-31 and SMI-34 immunoreactivity remained incomplete even after $5 \mathrm{~d}$ of incubation of FPLC-purified NF-H with high concentrations of phosphatase (Fig. 2). This behavior resembled somewhat that of the NF-H subunit in the reconstituted NF triplet (Fig. 1, lanes A vs. lanes C). The immunoreactivity of purified NF-H with SMI-31/SMI-34 can only be removed with calf intestinal phosphatase after $5 \mathrm{~d}$ of incubation. The mobility of dephosphorylated NF-H with SDS-PAGE (Fig. 2, center panel, lane C) resembles that of native NF-M (lane A; lane B: native NF-H). NF-M can be completely dephosphorylated with both phosphatases under identical conditions (right panel).

Since the purified subunits of NF-M and NF-H are soluble and cannot be sedimented, the phosphatases had to be removed by gel filtration. Heat treatment (and freezing) of the NF was avoided because the proteins tended to aggregate.


Figure 1. Lanes: $A$, purified soluble NF-H; $B$, "native" NF triplet, reconstituted after HTP chromatography; $C$, NF triplet reconstituted from FPLC-purified subunits. Top, 7.5\% SDS-PAGE; middle, Western immunoblots with mAb SMI-31 (phosphorylated epitope); bottom, Western immunoblots with mAb SMI-33 (unphosphorylated epitope). All gels except the control were subjected to a brief electrophoretic transfer in SDS-free buffer to remove the phosphatase and accompanying impurities; NFs did not transfer under these conditions. Control, With the phosphatase activity inhibited by $10 \mathrm{~mm}$ phosphate and $5 \mathrm{~mm}$ EDTA, the NF proteins did not appear altered after $24 \mathrm{hr}$ of incubation.

\section{Detection of KSP-phosphorylating kinases in bovine brain by immunoassay}

In initial ${ }^{32} \mathrm{P}$ assays of crude whole-brain supernatants with and without common second messengers, NF phosphorylation was relatively weak with only a slight activation in the presence of cAMP. No gel shift of the heavy NF subunits could be demonstrated even after $12 \mathrm{hr}$ of incubation (not shown). Likewise, AS-concentrated fractions of supernatant and high salt cytoskeletal extract did not reveal any prominent NF-specific activity in initial rate assays. 


\section{NF-H}



Figure 2. Dephosphorylation of NF-H and NF-M by $E$. coli alkaline phosphatase or with calf intestinal phosphatase. Top, E. coli alkaline phosphatase; SDS-PAGE and immunodot blots with mAbs SMI-31 and SMI-34 (phosphorylated epitope). Lanes: $a, 1 \mathrm{hr} ; b, 24 \mathrm{hr}$; $c, 5 \mathrm{~d}$ of incubation at $37^{\circ} \mathrm{C} ; d$, control incubation for $5 \mathrm{~d}$ with the phosphatase blocked by $10 \mathrm{~mm}$ phosphate $(\mathrm{pH} 8.5)$ and 5 mM EDTA. Middle, SDS-PAGE. Lanes: $A$, native NF-M; $B$, native NF$\mathrm{H}$; $C$, dephosphorylated NF-H (E. coli alkaline phosphatase). Bottom, Calf intestinal phosphatase; immunodot blots with mAbs SMI-31 and SMI-34. Lanes $a-d$ are as above.
A B C
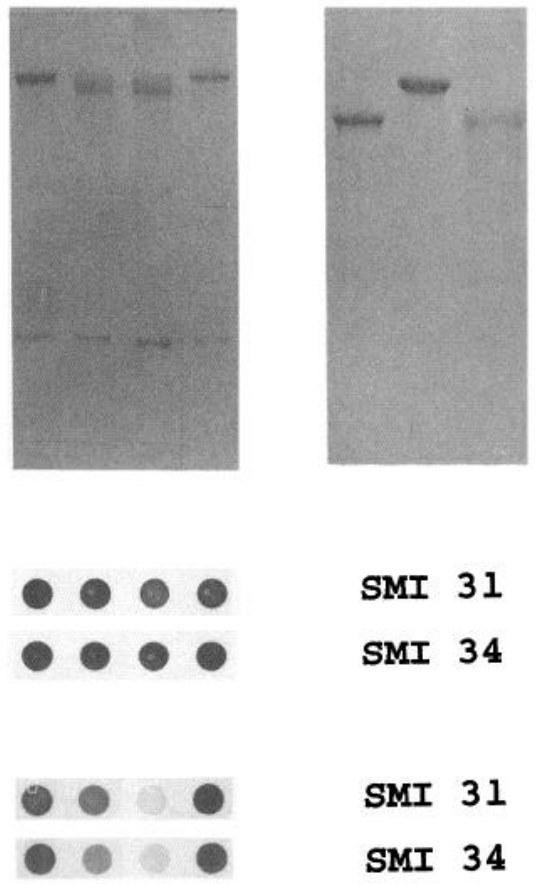

NF-M
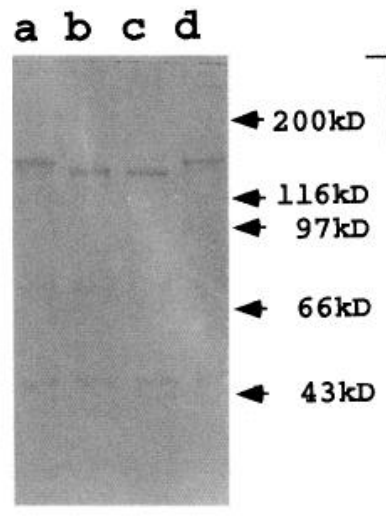

E.col

alk. phosph. calf intest. alk. phosph.

\section{SMI-31 and SMI-34 immunoassays detect a NF kinase not} associated with the cytoskeleton

The SMI-31 and SMI-34 epitopes could only be reconstituted after $18 \mathrm{hr}$ but not after $6 \mathrm{hr}$ of incubation of the dephosphorylated NF triplet with the $30-40 \%$ AS fraction of the brain supernatant. Later, a $35-45 \%$ fraction was found to be more favorable for preparative purposes. The activity was NF specific, since control immunoassays lacking dephosphorylated native NF triplet were negative, in contrast to the $40-50 \%$ fraction (Fig. $3 A$ ). An additional, less prominent NF-specific activity was detected in the $40-55 \%$ and $55-70 \%$ AS fractions of a cytoskeletal extract with $0.8 \mathrm{M} \mathrm{KCl}$, where we had expected the main NF kinase activity to be, judging from reports in the literature. The soluble nature of our kinase(s) was confirmed when the activity did not cosediment under low salt conditions (10 mM HEPES buffer, pH 7) after 15 min incubation with dephosphorylated native NF triplet at $37^{\circ} \mathrm{C}$ or with assembled cold-solubilized microtubules according to the method of Shelanski et al. (1973) (4 M glycerol, $\left.1 \mathrm{mM} \mathrm{GTP}, 37^{\circ} \mathrm{C}, 30 \mathrm{~min}\right)$, in the absence or presence of $5 \mathrm{~mm} \mathrm{Mg-ATP}$ (not shown).

\section{Optimization of the SMI-31 and SMI-34 immunoassays}

The site-specific kinase immunoassays, though only semiquantitative, allowed for the estimation of some of the properties of the enzyme(s) while still in a crude form (Fig. $3 B, C$ ). The $18 \mathrm{hr}$ incubation period was chosen for saturation assays to be consistent with the early experiments and to maximize phosphorylating activity. The $\mathrm{pH}$ optimum was around $\mathrm{pH} 7$; the best $\mathrm{Mg}^{2+}$ and ATP concentrations were found to be $2 \mathrm{mM}$ and 1 mM, respectively. ATP (5 mM) inhibited the activity. $\mathrm{Mn}^{2+}$ was about twice as effective as $\mathrm{Mg}^{2+}$ (not shown). GTP could not substitute for ATP. Concentrations of $\mathrm{NaCl}$ of $>20 \mathrm{~mm}$ diminished the assay response, due to either inhibition or destabilization of the activity during the lengthy incubation period. This effect was attributable to ionic strength rather than specifically to $\mathrm{Na}^{+}$or $\mathrm{Cl}^{-}$ions, since the same decline was seen with $\left(\mathrm{NH}_{4}\right)_{2} \mathrm{SO}_{4}$ at comparable ionic strength (not shown).

\section{Purification of the KSP-phosphorylating kinases}

To select for suitable adsorbents and elution conditions, the 35$45 \%$ AS fraction was exposed to a variety of chromatography media at $4^{\circ} \mathrm{C}$. The activity as assayed with the SMI mAbs was lost in almost every case. Even largely nonionic media like agarose, and to a lesser degree Sephadex, produced substantial losses. These losses occurred also in the presence of $4 \mathrm{M} \mathrm{NaCl}$, which by itself did not affect enzyme survival in control experiments. $\mathrm{NaCl}$ was added to prevent binding of the kinase or possible essential subunits to the chromatography media. However, inclusion of Mg-ATP stabilized the activity on some media but not others. In order of decreasing survival of activity, Sephadex, agarose, CM-Sepharose, and quarternary ammonium anion exchangers were found to be the only useful chromatography media in the presence of $\mathrm{Mg}$-ATP. In a small-scale gel filtration of the $35-45 \%$ AS fraction on Sephadex under low salt conditions, a major activity peak of $50-60 \mathrm{kDa}$ and a minor activity peak around $30-40 \mathrm{kDa}$ were found both by ${ }^{32} \mathrm{P}$ assay, followed by SDS-PAGE, and by SMI immunoassays.

\section{Chromatography on CM-Sepharose}

The activity was enriched about five- to sixfold before gel filtration by chromatography of the AS fraction on CM-Sepharose at pH 6.0 with $5 \mathrm{~mm} \mathrm{Mg-ATP}$ and $10 \%$ glycerol as stabilizing agents. The NF-specific kinase activity was eluted in one step 

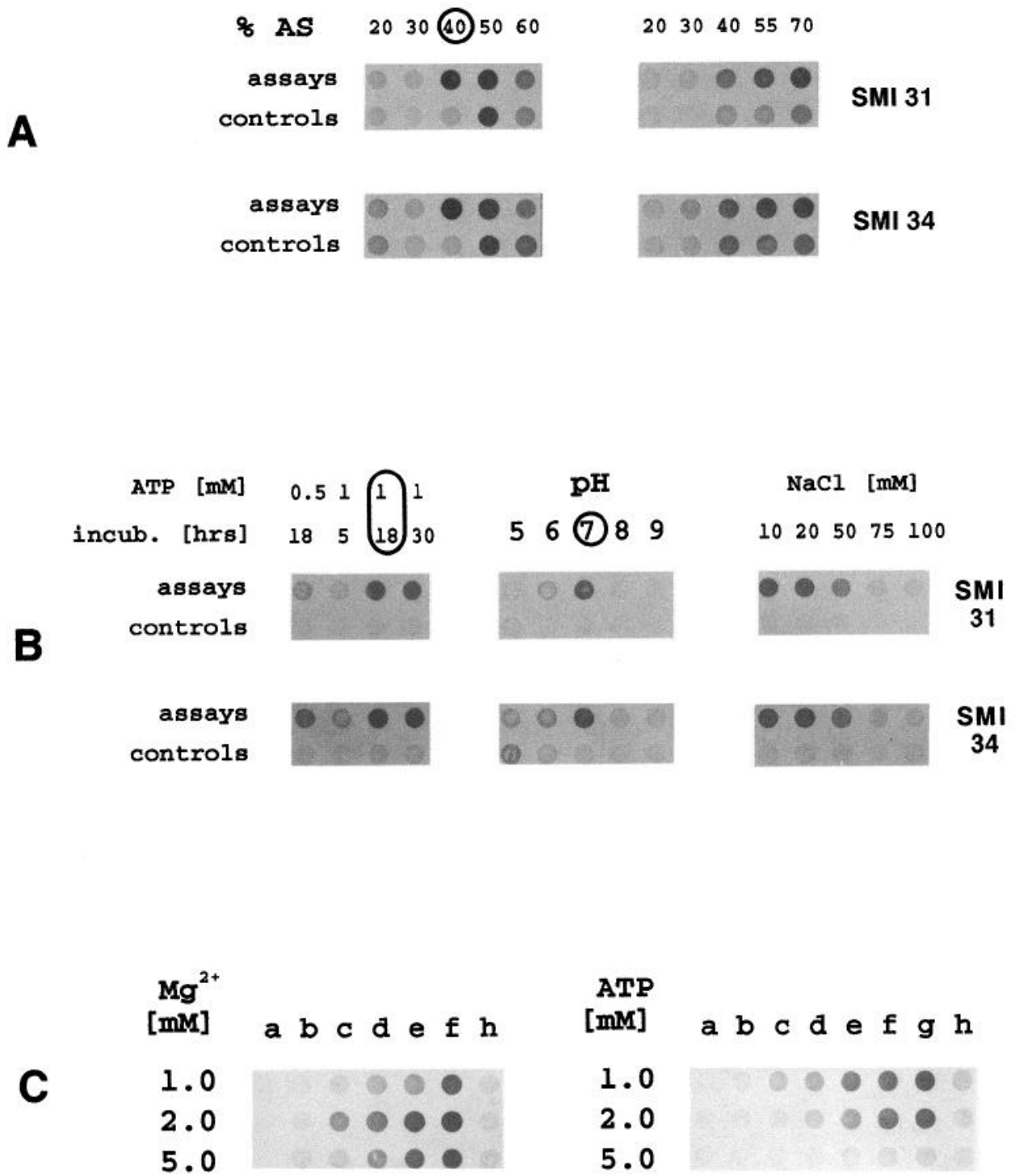

\begin{abstract}
Figure 3. A: Left, Immunodot blot assays ( $0.5 \mathrm{~mm} \mathrm{Mg}^{2+}, 0.5 \mathrm{~mm}$ ATP) of AS fractions from whole-brain supernatant. Control assays have no added NF proteins. Right, Imunodot blot assays of AS fractions from a $0.8 \mathrm{M} \mathrm{KCl} \mathrm{cy-}$ toskeletal extract. $B$, Time, $\mathrm{pH}$, and ionic strength requirements of the SMI31 and SMI-34 immunoassays. The assay responses were optimal at $\mathrm{pH} 7.0$, low salt conditions, $1 \mathrm{~mm}$ ATP. All assays were performed for $18 \mathrm{hr}$ with 0.5 $\mathrm{mM} \mathrm{Mg}{ }^{2+}$ when not indicated differently. $C$, Optimization of the SMI-31 immunoassay (identical results were obtained with SMI-34) with respect to $\mathrm{Mg}^{2+}$ (left; $1 \mathrm{~mm}$ ATP) and ATP concentrations (right; $2 \mathrm{~mm} \mathrm{Mg}^{2+}$ ) by determination of the lowest concentration of crude enzyme ( $40 \%$ AS cut) required for assay response. $a-g: 0.04,0.09,0.13$, $0.18,0.22,0.33$, and $0.44 \mu \mathrm{g}$ of crude enzyme protein per assay, respectively. $h$, Control assay without NFs; $0.4 \mu \mathrm{g}$ of crude enzyme protein per assay.
\end{abstract}

by raising the $\mathrm{Mg}$-acetate concentration to $85 \mathrm{~mm}$. Elution with a gradient of $\mathrm{Mg}$-acetate resulted only in a broader peak of activity but did not improve the enrichment. Little NF-specific activity was found in the flow-through.

\section{Several kinase activities are resolved by gel filtration and Mono- $Q F P L C$}

Gel filtration proved to be the most effective step in the purification scheme and was carried out in the presence of Mg-ATP on superfine grade of Sephadex. The activity as assayed by ${ }^{32} \mathrm{P}$ incorporation into dephosphorylated native NF triplet and by SMI immunoassays eluted in most cases as one very broad peak (Fig. 4), sometimes a major and a minor activity were resolved with apparent $M_{r}$ of 60,000 and 40,000 , respectively. No significant NF-specific phosphatase activity could be detected in the relevant kinase fractions by monitoring the liberation of phosphate under assay conditions from ${ }^{32} \mathrm{P}$-labeled dephosphorylated native NF triplet, prepared by phosphorylation with partially purified NF kinase.

Initially, all fractions containing high amounts of SMI-31 epitope reconstituting activity were pooled (method B) and sub- jected to FPLC on Mono-Q with a linear gradient of $\mathrm{MgCl}_{2}$. A $40 \mathrm{kDa}$ band (PK40) with SDS-PAGE analysis of the fractions matched very closely the activity profile (not shown). However, subsequent detailed analysis (see below) revealed the presence of two more distinct activities in the gel filtration fractions; one of them was correlated with a $36 \mathrm{kDa}$ protein (PK36), which contaminated PK40 (PK36/40; see Fig. 5C, lane a). Separation of PK 36 and PK40 was accomplished on Mono-Q by a modified gradient profile with an isocratic component (method B). However, both kinases were obtained only in relatively low purity, and a preparative gel electrophoresis in the presence of Mg-ATP was required to yield PK40 in the highest purity (Table 1; Fig. $5 C$, lane b) achieved so far. This preparation was used to characterize PK40.

Alternatively, gel filtration fractions were pooled according to their content of the 40 and $36 \mathrm{kDa}$ protein known to be associated with kinase activity (Fig. 4; method A). Subsequent elution of each kinase from Mono-Q with the modified gradient profile (Fig. 6) rendered PK40 in a purity comparing well to electrophoretically purified material (Table 1; Fig. 5C, lane c) and PK36 in the highest purity obtained so far (Fig. $5 \mathrm{C}$, lane 
Figure 4. Analysis of gel filtration fractions $10-28$ by SMI-31/SMI-34 immunoassays after $18 \mathrm{hr}$ of incubation with NF triplet (top), by ${ }^{32} \mathrm{P}$ assays after 30 min of incubation with NF triplet (middle), and by $12 \%$ SDS-PAGE (bottom). In method A (Materials and Methods), fractions 17-19 and 21-22 were pooled according to the most prominent occurrence of PK40 and PK36 (arrowheads; see Fig. 5). In method B (Materials and Methods), fractions $12-22$ were pooled as indicated by the SMI-31 immunodot blot assays.

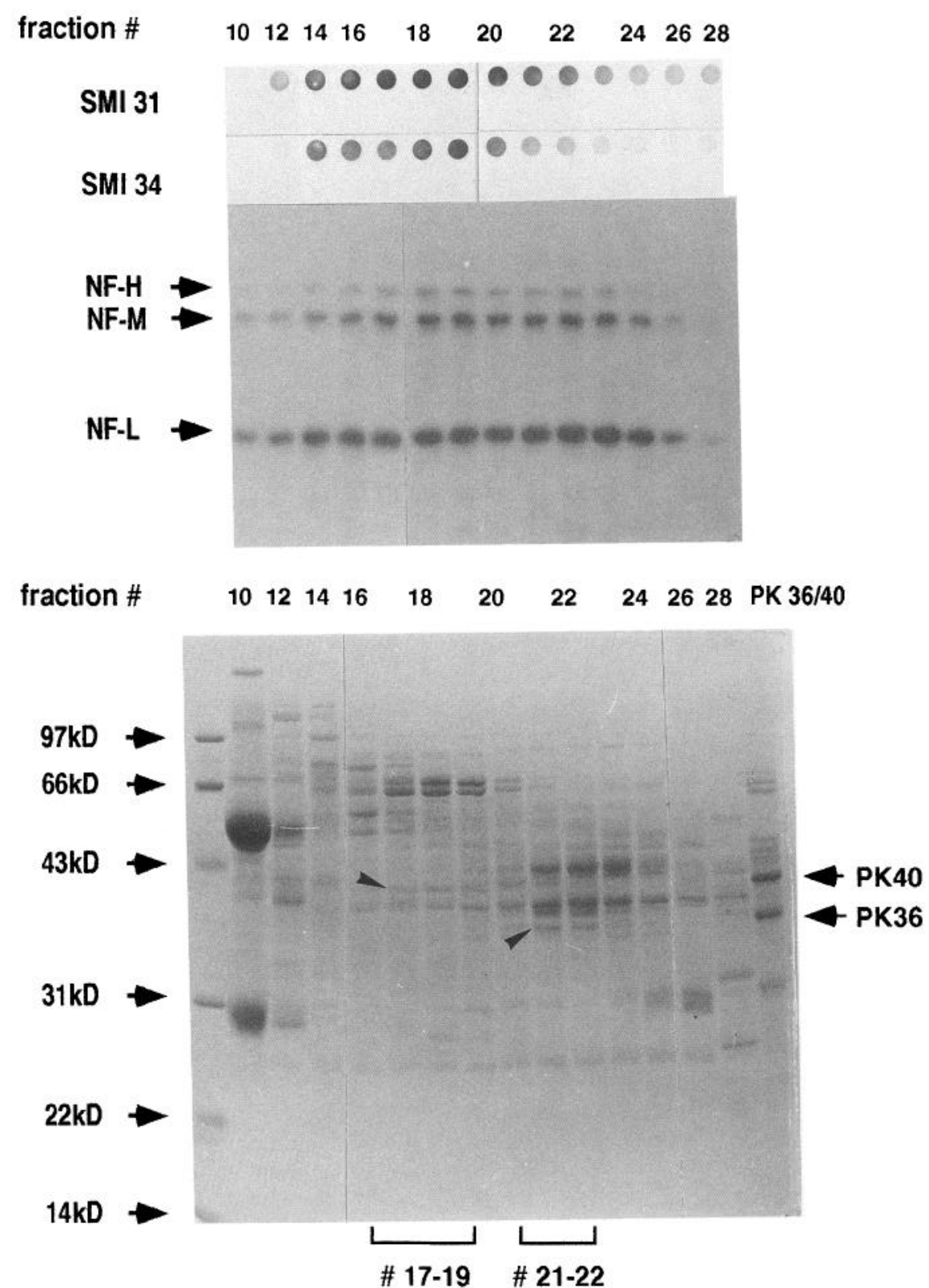

d). Preparative electrophoresis of PK40 resulting from this method did not improve the purity significantly. Efforts to purify PK40 and PK36 further by FPLC on Mono-S resulted in complete loss of activity even in the presence of Mg-ATP.

A third uncharacterized kinase activity was found in gel filtration fractions after the broad activity peak and was sometimes seen as a separate peak of activity. Significant reconstitution of the SMI epitopes by this activity occurred only after concentration of these fractions (relatively weak immunoassays of fractions 23-25, Fig. 4). The activity eluted from Mono-Q at somewhat lower ionic strength than PK40 or PK36 with $>90 \%$ loss of the activity loaded (not shown). No band on silver-stained SDS-PAGE of concentrated fractions could be matched to the activity elution profile of the third kinase. The activity migrated over a wide range of mobilities on a nondenaturing PAGE, suggesting that it might represent a heterogeneous mixture of degradation products but probably unrelated to PK40 or PK36 (see below). Pooling of PK40 and PK36 in the gel filtration and FPLC steps according to method A precluded contamination with this kinase.

\section{Correlation of $a 40$ and a $36 \mathrm{kDa}$ protein with $\mathrm{NF}$ kinase activity}

The Mono-Q elution profile of PK36/40 (Fig. 5C, lane a; see Materials and Methods) strongly suggested association of a 40 kDa protein with NF kinase activity (not shown). To confirm this assignment further and to assess homogeneity of activity, PK36/40 was subjected to electrophoresis on SDS-free polyacrylamide gel in the presence of Mg-ATP to stabilize the kinase. Consecutive slices of the gel were extracted (see Materials and Methods) and analyzed for kinase activity by ${ }^{32} \mathrm{P}$ assay and immunoassay and for protein content by SDS-PAGE. The 40 $\mathrm{kDa}$ band correlated with activity as expected (Fig. $5 A$ ); how- 
A



$\begin{array}{lllllllll}37 & 39 & 41 & 43 & 45 & 47 & 49 & 51 & {[\mathrm{~mm}]}\end{array}$



B

SDS-

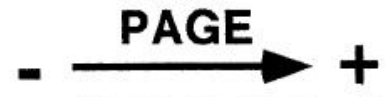

19212325 [mm]

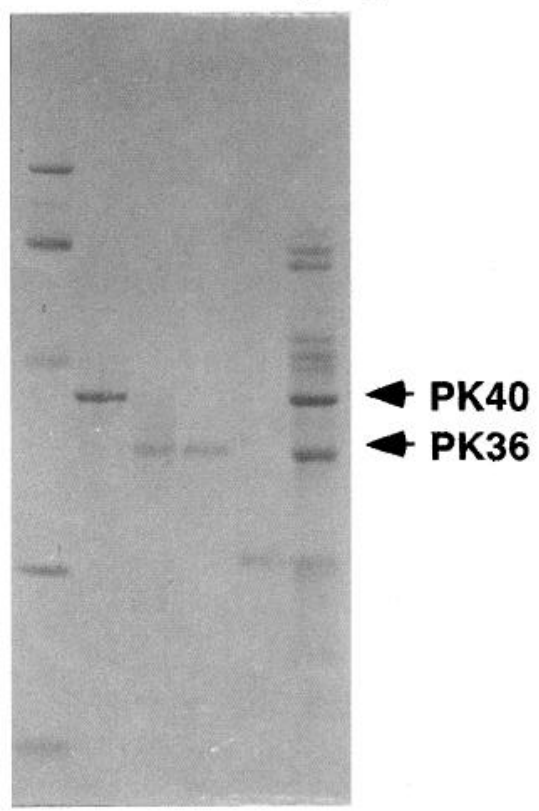

a b $\quad c \quad d$



Figure 5. Identification of a 40 and a $36 \mathrm{kDa}$ protein as kinases. $A$, The PK36/40 mixture (as in step IV, method B; see Materials and Methods) was separated on nondenaturing $7.5 \%$ polyacrylamide gel electrophoresis of $110 \mathrm{~mm}$ length containing Mg-ATP. Slices (2 mm) were each partially eluted to assay for NF kinase activity by the ${ }^{32} \mathrm{P}$ assay, followed by SDS-PAGE and radioautography. This correlated well with the $40 \mathrm{kDa}$ protein content of the slices analyzed by $12 \%$ SDS polyacrylamide gel electrophoresis. A $36 \mathrm{kDa}$ band was eluted in slices $>49$ mm from the top but showed only weak enzymatic activity, perhaps due to inefficient elution from gel slices. B, The PK $36 / 40$ mixture was separated on a $10 \%$ polyacrylamide gel containing SDS and Mg-ATP. Slices $(2 \mathrm{~mm})$ were analyzed as in $A$. Only the $36 \mathrm{kDa}$ band shows activity after contact with SDS . However, $24 \mathrm{hr}$ of exposure of the radioautograph was needed as opposed to only $2 \mathrm{hr}$ in $A$, again pointing to a relatively low recovery of PK 36 by elution of gel slices. Note that phosphorylation of NF-H is seen with PK40 but not PK36. C, Comparison by SDS-PAGE and staining with Coomassie blue of several NF kinase preparations. Lane a was obtained by pooling of PK40 and PK36 after gel filtration and elution from Mono-Q with an uninterrupted linear gradient; lane b, PK40 obtained by preparative gel electrophoresis (step V in method B). This preparation was used for characterization purposes. PK40 (lane c) and PK36 (lane d) were obtained after pooling of gel filtration fractions and Mono-Q elution protocol according to method A. Preparative gel electrophoresis of preparation $c$ did not improve the purity beyond $b$.

ever, another activity was detected in a broad range of higher relative mobility with PAGE than PK40 (not shown).

A clearer identification of PK36 was possible when PK36/40 was separated with SDS-PAGE in the presence of Mg-ATP and gel slices were analyzed as above. In this case, only the $36 \mathrm{kDa}$ protein retained NF kinase activity, while the activity of the 40
$\mathrm{kDa}$ protein could not be reconstituted after SDS exposure (Fig. $5 B)$.

Both kinases, PK40 and PK36, also reconstituted the epitope of RT97 (data not shown), another mAb recognizing the MPR sequence (Lee et al., 1988).

$\mathrm{N}$-terminal sequencing of the two proteins failed, probably 

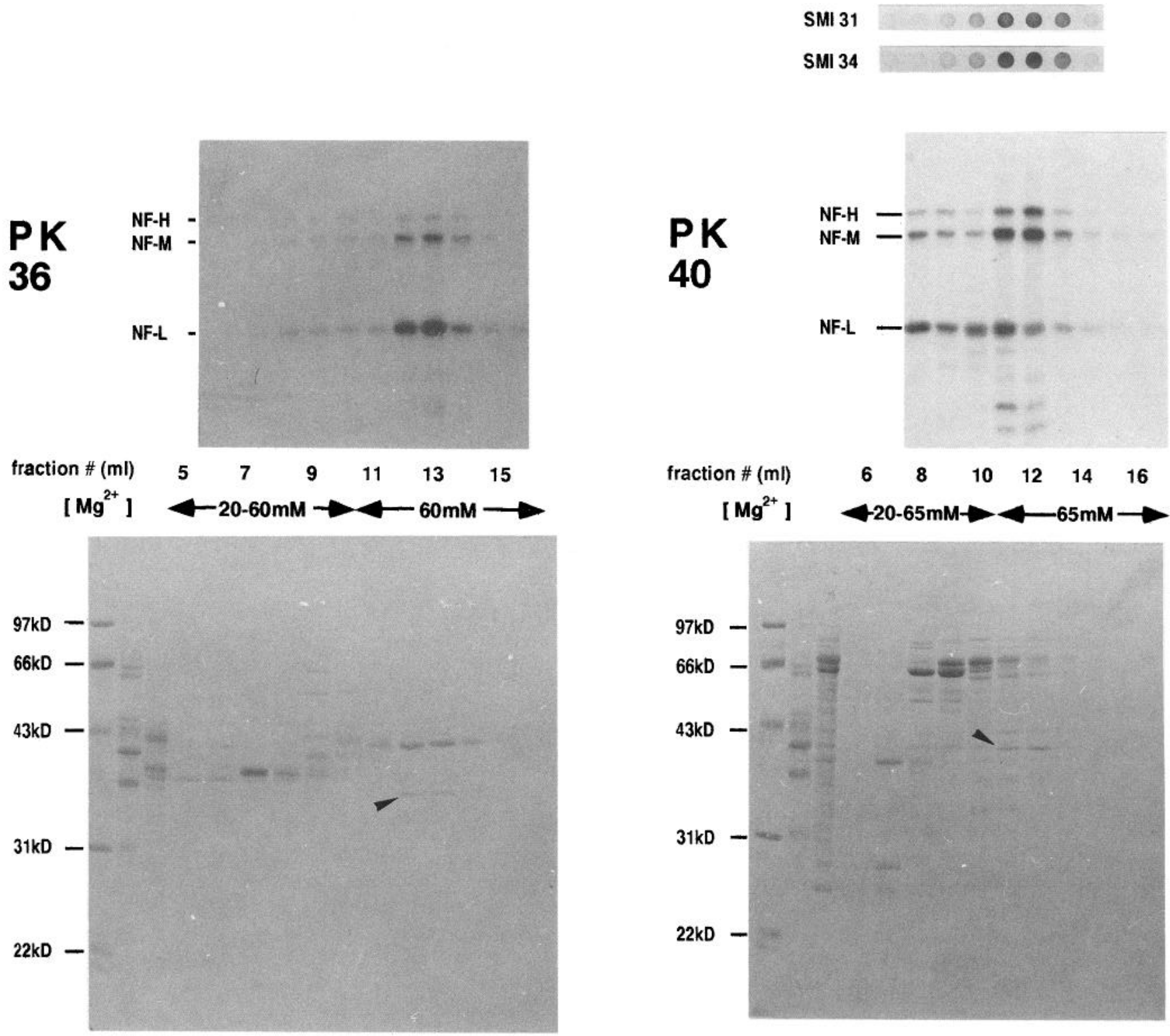

Mono Q of \# 21-22 (Fig. 5)

Figure 6. Elution of PK36 and PK40 from Mono-Q with a $\mathrm{MgCl}_{2}$ gradient. Peaks of activity in the ${ }^{32} \mathrm{P}$ assays and immunoassays correlated well with the 36 and $40 \mathrm{kDa}$ bands, respectively (arrowheads). The immunoassays responded only weakly to PK 36 . Note again the relatively prominent phosphorylation of NF-M and NF-H by PK40. The weaker activity in fractions 8-10 of the PK40 elution may be correlated with a band that has a slightly higher apparent $M_{r}$ on $12 \%$ SDS-polyacrylamide gel than PK40 and was therefore not combined with PK40. Pooling of PK40 fractions 11 and 12 and PK 36 fractions 12 and 13 resulted in preparations $c$ and $d$ in Fig. $5 C$.

as a result of blocked N-termini, which are common in mammalian proteins.

\section{Characterization of PK40 and PK36}

\section{Substrate specificity of $P K 40$ and $P K 36$}

Lysine-rich histone type III was found to be the most preferred substrate of both kinases and might be more favorable for assay purposes than NF. The acidic protein phosvitin and tubulin were very poor substrates.

Among neuronal proteins tested, the specificity of PK40 for dephosphorylated NF-M is most striking (Fig. 7). Other sub- strates are less efficient, in the following order: dephosphorylated $\mathrm{NF}-\mathrm{M} \gg \mathrm{tau}>\mathrm{NF}-\mathrm{M}=\mathrm{NF}-\mathrm{L}>$ dephosphorylated NF-H $>$ NF-H.

PK36 has a lower specific activity; its substrates form a somewhat different sequence: NF-L $=$ tau $=$ dephosphorylated NF-M $>$ NF-M $\gg$ NF-H = dephosphorylated NF-H.

The third uncharacterized activity from the gel filtration (see above) phosphorylated the heavy NF subunits less well than NF-L, especially when these had been dephosphorylated, but had a significant specificity for phosvitin, suggesting that it might not be related to either PK40 or PK36 (not shown). 


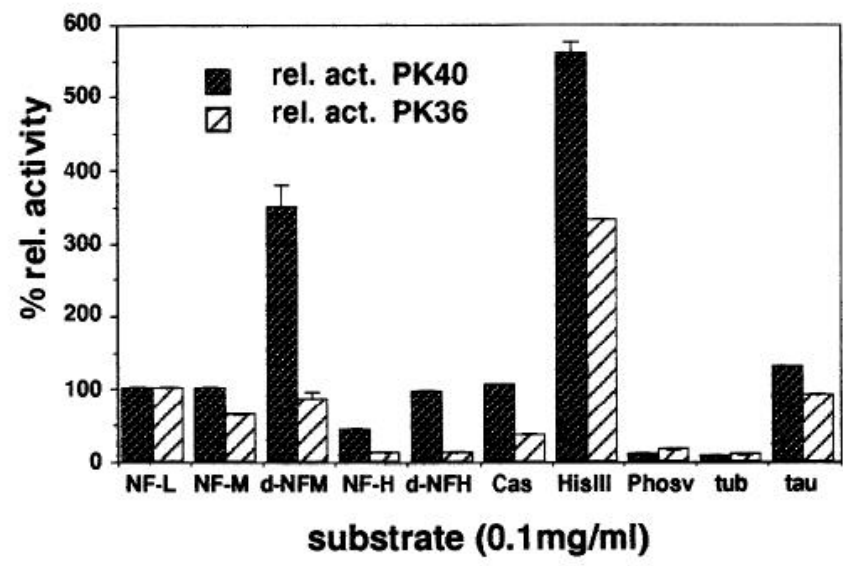

Figure 7. Specificity of the kinases PK40 and PK36 (see Fig. 5C, lanes $\mathrm{b}$ and $\mathrm{d}$, and Table 1 for preparations used) for various neuronal proteins (see text) and general kinase substrates (see text) relative to NF-L. The ${ }^{32} \mathrm{P}$ assay of kinase activity was used (see Materials and Methods). The indicated values are means $( \pm \mathrm{SD})$ of triplicate assays. Note the striking preference of PK40 for dephosphorylated NF-M and the level of tau specificity of both kinases.

Some microtubule-associated proteins (MAPs) are also good substrates for both kinases. Two chromatographically separable tau preparations (taus I and II; see Materials and Methods) were equally well phosphorylated by PK40 and PK36. No tau isoform specificity was detectable in either case (Fig. 8, lanes a,b). MAP2 in a crude microtubule preparation was a substrate comparable to the tau proteins or better, especially for PK40 (see difference between lanes $\mathrm{c}$ and d, Fig. 8).

\section{ATP dependence and inhibition of the activity of $P K 40$ and PK36}

The ATP dependence of the activities of PK40 and PK36 was determined at $2 \mathrm{mM} \mathrm{Mg}{ }^{2+}$ and with soluble dephosphorylated NF-M as second substrate to avoid uncertainties arising from the aggregation state of NF triplet in suspension (Fig. 9). The

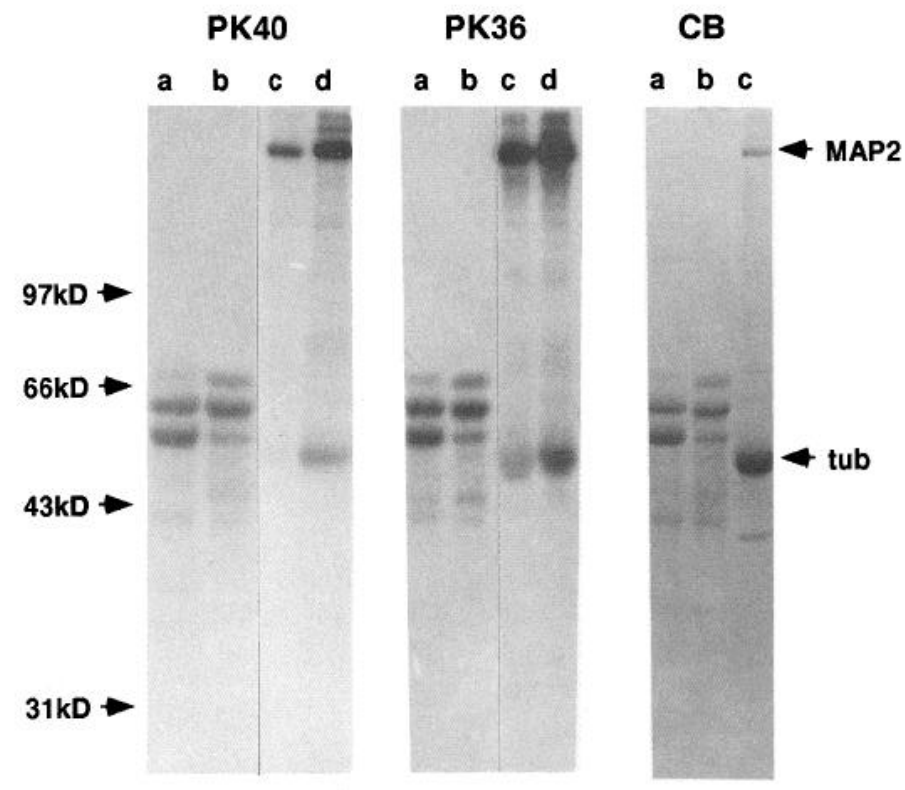

Figure 8. Comparison of MAPs on autoradiograms after phosphorylation with PK40 and PK36 or microtubule-associated kinase activity. Two distinct bovine tau fractions, tau I (lanes $a$ ) and tau II (lanes $b$; see Materials and Methods) were good substrates for PK40 as well as PK36. Comparison with the Coomassie blue-stained gel $(C B)$ revealed no preference for any isoform of tau. MAP2 is phosphorylated by both kinases (lanes d) above background level (PK40, 2.5×; PK36, 1.5×; determined by Cerenkov counting). Background labeling of MAP2 is due to a second messenger-independent activity intrinsic to cycled microtubules (lanes $c$ ). tub, tubulin.

optima were at $0.5-1 \mathrm{~mm}$ ATP for both kinases, which confirmed the concentration suggested earlier for the crude enzymes by the semiquantitative SMI immunoassays (see above). Apparent $K_{m}$ values for ATP of both kinases were estimated from Woolf-Hanes plots (Dixon and Webb, 1979) for a range of ATP concentrations sufficiently below the onset of inhibition (Fig. 9). Three determinations of the $K_{m}$ of PK40 at three different

Table 1. Enrichment of PK40 and PK36 through various chromatographic steps by alternative methods A (standard) and B

\begin{tabular}{|c|c|c|c|c|c|c|c|}
\hline \multirow[b]{2}{*}{ Step } & & \multicolumn{2}{|c|}{$\begin{array}{l}\text { Specific activity }{ }^{a} \\
(\mathrm{nmol} / \mathrm{min} / \mathrm{mg})\end{array}$} & \multicolumn{2}{|c|}{$\begin{array}{l}\begin{array}{l}\text { Total activity } \\
\text { (nmol/min) }\end{array} \\
\end{array}$} & \multicolumn{2}{|c|}{$\begin{array}{l}\text { Amount retrieved } \\
\text { (mg) }\end{array}$} \\
\hline & & PK40 & PK36 & PK40 & PK36 & PK40 & PK36 \\
\hline I & AS fractionation & $-^{c}$ & - & - & - & & \\
\hline II & CM-Sepharose & \multirow{2}{*}{\multicolumn{2}{|c|}{0.55}} & \multirow{2}{*}{\multicolumn{2}{|c|}{23.6}} & \multicolumn{2}{|c|}{43} \\
\hline \multirow[t]{3}{*}{ III } & Sephadex G200 & & & & & & \\
\hline & Method A & 1.45 & 1.15 & 3.80 & 2.27 & 2.6 & 2.0 \\
\hline & Method B & \multicolumn{2}{|c|}{0.26} & \multicolumn{2}{|c|}{4.5} & \multicolumn{2}{|c|}{17.5} \\
\hline \multirow[t]{3}{*}{ IV } & Mono-Q FPLC & & & & & & \\
\hline & Method A & 3.8 & 2.8 & 0.73 & 0.39 & 0.19 & 0.14 \\
\hline & Method B & 0.83 & 0.28 & 0.78 & 0.47 & 0.94 & 1.7 \\
\hline \multirow[t]{2}{*}{$\mathrm{v}$} & $\begin{array}{l}\text { Preparative Gel } \\
\text { electrophoresis }\end{array}$ & & & & & & \\
\hline & (method B only) & 5.2 & $-^{d}$ & 0.67 & - & 0.13 & - \\
\hline
\end{tabular}

Method A: gel filtration fractions analyzed by SDS-PAGE were pooled to contain either the 36 or the $40 \mathrm{kDa}$ band (see fig. 4). Method B: all fractions containing SMI31/SMI-34 epitope reconstituting activity were pooled after gel filtration, and PK 36 and PK40 were separated in the subsequent step.

${ }^{a} \mathrm{nmol}$ of ${ }^{32} \mathrm{P}_{-} \mathrm{PO}_{4}$ transferred $/ \mathrm{min} / \mathrm{mg}$ protein.

${ }^{6} \mathrm{nmol}$ of ${ }^{32} \mathrm{P}_{-} \mathrm{PO}_{4}$ transferred/min.

' Not determined; NF-specific activity too low against background.

${ }^{d}$ Electroelution of PK36 from a preparative SDS gel was unsuccessful. 
PK40
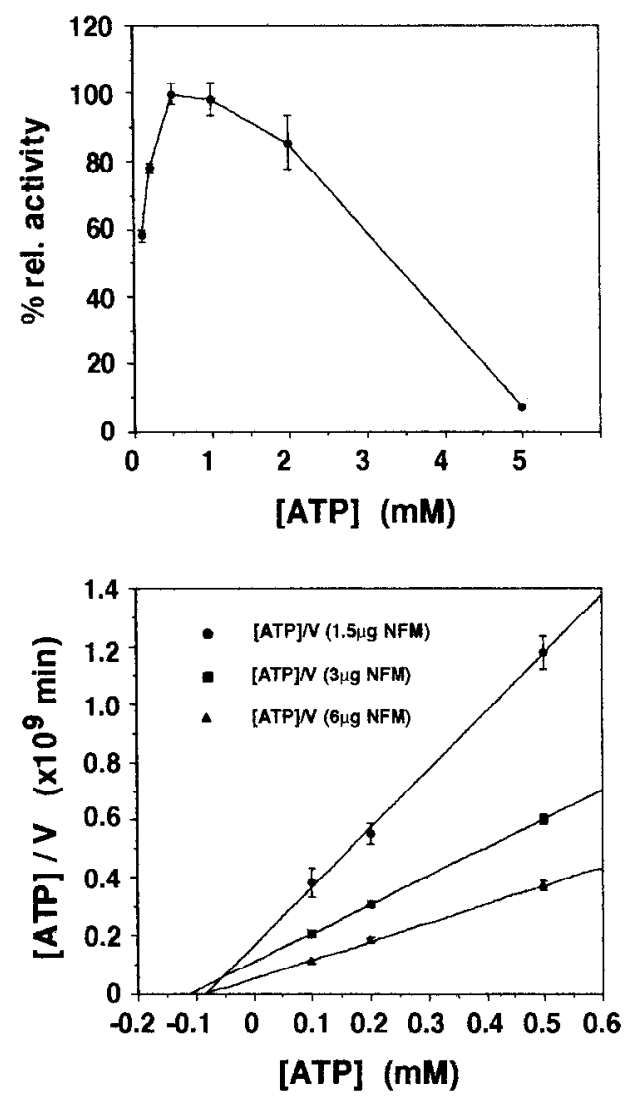

PK36
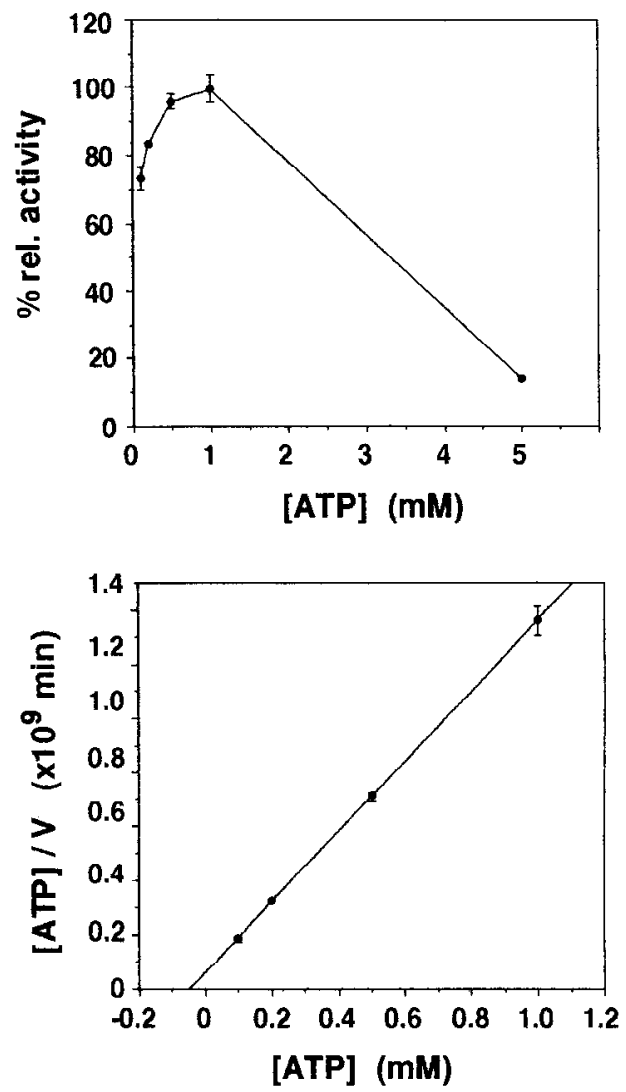

Figure 9. Top, Dependence of activity on ATP concentration at a $\mathrm{Mg}^{2+}$ concentration of $2 \mathrm{~mm}$. Bottom, HanesWoolf plots for PK40 and PK36 with NF-M as substrate. Error bars are \pm SD. concentrations of the second substrate, NF-M, gave similar values (mean $\pm \mathrm{SD}, 93 \pm 12 \mu \mathrm{M}$ ), indicating little influence of the concentration of NF-M on ATP affinity of PK40. The apparent $K_{m}$ of PK36 is approximately $50 \mu \mathrm{M}$.

PK36 and particularly PK40 were strongly inhibited to $14 \%$ and $7 \%$, respectively, of the control level in the presence of 5 mM ATP amounting to $3 \mathrm{~mm}$ excess of free (uncomplexed) ATP over $\mathrm{Mg}^{2+}$. In contrast, with excess $\mathrm{Mg}^{2+}$ ( $5 \mathrm{~mm}$ over $\left.1 \mathrm{mM} \mathrm{ATP}\right)$ or $5 \mathrm{~mm} \mathrm{Mg} \mathrm{Mg}^{2+} / 5 \mathrm{mM}$ ATP, little or no inhibition was observed for PK40, while the activity of PK36 was significantly reduced under these conditions (Table 2).

The activity of the kinases was also reduced to $27 \%$ (PK40) and $40 \%$ (PK36) in the presence of $150 \mathrm{~mm} \mathrm{NaCl}$. Inhibition by $\mathrm{NaCl}$ in this concentration range has been observed with other kinases also, among them cAMP-dependent kinase (Moll and Kaiser, 1977) and a nuclear casein kinase from HeLa cells (Friedrich and Ingram, 1989). None of the above effects could be explained by destabilization of the enzymes, since preincubations without substrate for $1 \mathrm{hr}$ under inhibiting conditions, dialysis, and subsequent assay of remaining activity for $15 \mathrm{~min}$ under standard conditions did not reveal losses very much beyond control levels (Table 2, preincubation). Inhibition by the Walsh inhibitor was seen only for PK36, but not PK40, with an estimated $\mathrm{IC}_{50}$ of $50 \mu \mathrm{M}$. No significant activity change was seen over a wide range of concentrations of both kinases, indicating that regulatory mechanisms like homomer formation or intermolecular autophosphorylation probably do not play a role.
Certain olher kinases do not phosphorylate the MPR site of NF proteins

We tested several common neuronal kinases and also a mixture of PK40 and PK36 (PK36/40) under comparable conditions for phosphorylation of the KSP sequence in dephosphorylated NF triplet and dephosphorylated NF-M, using the SMI-31 immunoassay. While calcium/calmodulin-dependent kinase II and protein kinase $\mathrm{C}$ phosphorylated native NF triplet relatively weakly, all NF subunits were very good substrates for the catalytic subunit of the cAMP-dependent kinase. However, reconstitution of the SMI epitopes in dephosphorylated NF triplet or purified dephosphorylated NF-M was only possible with PK36/ 40 , even when much less activity was used than of the former kinase (Fig. 10). Incubation with the second messenger-independent kinase and the cAMP-dependent activity known to be associated with microtubules (Leterrier et al., 1981) did not increase the response in the immunoassay significantly above the level seen with microtubules alone in the absence of exogenously added NF, although all subunits were strongly ${ }^{32} \mathrm{P}$ labeled.

\section{PK40 and PK36 induce mobility shifts of the heavy NF subunits on SDS-PAGE and incorporate phosphate in high molar ratios}

To determine the maximum number of phosphates incorporated into the heavy NF subunits by PK40 and PK36, the purified activities (Fig. $5 C$, lanes b,d) were incubated in increasing 
concentrations with dephosphorylated NF-M and dephosphorylated NF-H (Fig. 11). The stoichiometry of phosphorylation was determined by assuming that the correct molecular masses of NF-M and NF-H are 110 and $140 \mathrm{kDa}$, respectively, as determined by Kaufmann et al. (1984), since SDS-PAGE considerably overestimates their $M_{r}$. PK40 incorporated up to 15 phosphate groups into NF-M, which corresponds well to the number of phosphates found in isolated bovine NF-M (Wong et al., 1984) and induced a complete shift of the NF-M band on SDS-PAGE to the higher apparent $M_{r}$ of native NF-M. In contrast, only a partial shift of NF-H was achieved with a maximum of seven phosphates introduced into a molecule with presumably about $40 \mathrm{KSP}$ sites (Fig. 11A). The phosphorylation of NF-M with PK36 appeared to be saturated at 10 mol phosphate/mol NF-M with a substantial gel mobility shift; however, the NF-M band remained diffuse, possibly due to a heterogeneous phosphorylation state (Fig. $11 B$ ). NF-H was not phosphorylated very well by PK36 and showed virtually no gel shift, in correlation with its poor substrate properties for PK36. Both kinases reconstituted the SMI epitopes, but only weakly in the case of NF-H and PK36.

The maximal phosphorylation of NF-M was not significantly higher with a mixture of the two kinases (PK36/40), indicating that PK40 and PK36 might have a largely overlapping site specificity on NF-M. After incorporation of 7-13 phosphates, NF-M had a gel mobility comparable to native NF-M (Fig. 11C). The SMI immunoassay responses were correlated with the gel mobility shift but did not respond at lower levels of phosphorylation of $<5 \mathrm{~mol} \mathrm{PO}_{4} / \mathrm{mol} \mathrm{NF}$-M. Interestingly, the SMI-34 immunoassay required a higher level of phosphorylation than the SMI-31 assay.

\section{PK40 induces a substantial shift of apparent $M_{r}$ of tau} proteins with SDS-PAGE

Incubation of native bovine tau with a mixture of bacterial and calf intestinal alkaline phosphatases converted the pattern of three distinguishable isoforms from SDS-PAGE into a fourband pattern as expected (Lindwall and Cole, 1984), accompanied by a shift of about $15 \mathrm{kDa}$ to a lower apparent $M_{r}$ (Fig. $12 \mathrm{~A}$, lanes $\mathrm{c}, \mathrm{d})$. This shift could be completely reversed and the original three-band pattern restored after phosphorylation with

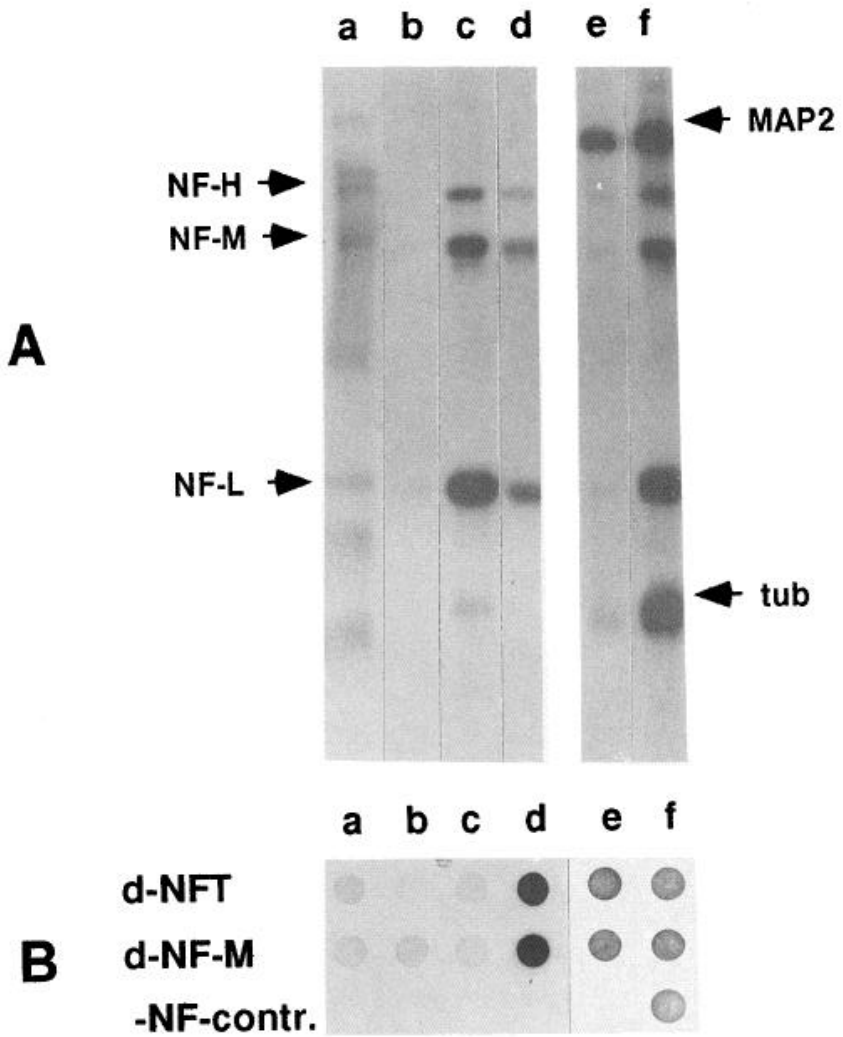

Figure 10. $A,{ }^{32} \mathrm{P}$ assays $(a-d, 1 \mathrm{hr} ; e$ and $f, 15 \mathrm{~min}$ ) with native NF triplet. $B$, SMI-31 immunoassays after $16 \mathrm{hr}$ of incubation with dephosphorylated NF triplet $(d-N F T)$ and dephosphorylated NF-M $(d-N F$ $M)$ as substrates. $a$, Calcium/calmodulin-dependent kinase II $(0.6 \mu \mathrm{g})$; $b$, protein kinase $\mathrm{C}(0.05 \mu \mathrm{g})$; $c$, catalytic subunit of cAMP-dependent kinase $(0.1 \mu \mathrm{g}) ; d$, a mix of PK40 and PK36, as used in Figure $5 C$,a $(0.13 \mu \mathrm{g}) ; e$, second messenger-independent, microtubule-associated kinase (30 $\mu \mathrm{g}$ of twice-cycled microtubules); and $f$, cAMP-dependent, microtubule-associated kinase ( $30 \mu \mathrm{g}$ of twice-cycled microtubules, activated by $50 \mu \mathrm{M}$ cAMP). $-N F$-contr., control without NF proteins.

PK40. The kinase also incorporated substantial amounts of phosphate into native bovine tau but induced only a small additional mobility shift. Preparations of bovine tau were previously found to contain five isoforms distinguishable with one-

Table 2. Effect of sodium chloride, excess magnesium and ATP, and the Walsh inhibitor on the relative activity (\%) and stability of PK40 and PK36

\begin{tabular}{|c|c|c|c|c|c|c|c|c|}
\hline & \multirow{2}{*}{$\begin{array}{l}\text { Control: } \\
2 \mathrm{mM} \mathrm{Mg}^{2+} \\
1 \mathrm{~mm} \text { ATP }\end{array}$} & \multirow{2}{*}{$\begin{array}{l}2 \mathrm{mM} \mathrm{Mg}^{2+} \\
5 \mathrm{~mm} \text { ATP }\end{array}$} & \multirow{2}{*}{$\begin{array}{l}5 \mathrm{mM} \mathrm{MG}^{2+} \\
1 \mathrm{~mm} \text { ATP }\end{array}$} & \multirow{2}{*}{$\begin{array}{l}5 \mathrm{~mm} \mathrm{Mg} \mathrm{Mg}^{2+} \\
5 \mathrm{mM} \text { ATP }\end{array}$} & \multirow{2}{*}{$\begin{array}{l}\mathrm{NaCl} \\
150 \mathrm{~mm} \\
\end{array}$} & \multicolumn{3}{|c|}{ Walsh inhibitor $(\mu \mathrm{M})$} \\
\hline & & & & & & $\overline{4.5}$ & 15 & 45 \\
\hline PK40 $0^{b}$ & $100^{c} \pm 6.9$ & $7.2 \pm 0.6$ & $107 \pm 3.5$ & $78 \pm 7.1$ & $27 \pm 1.8$ & $102 \pm 5.3$ & $107 \pm 3.7$ & $101 \pm 1.1$ \\
\hline \multirow[t]{5}{*}{ PK $36^{b}$} & $100 \pm 1.1$ & $14 \pm 0.5$ & $40 \pm 0.2$ & $38 \pm 2.2$ & $40 \pm 0.8$ & $103 \pm 0.5$ & $87 \pm 0.6$ & $58 \pm 3.3$ \\
\hline & & \multicolumn{7}{|c|}{$1 \mathrm{hr}$ preincubation ${ }^{a}$ with } \\
\hline & & \multicolumn{2}{|l|}{$\begin{array}{l}2 \mathrm{~mm} \mathrm{Mg} \mathrm{Mp}^{2+} \\
1 \mathrm{~mm} \text { ATP }\end{array}$} & \multicolumn{2}{|l|}{$\begin{array}{l}2 \mathrm{~mm} \mathrm{Mg}^{2+} \\
5 \mathrm{~mm} \text { ATP } \\
\end{array}$} & \multicolumn{2}{|l|}{$\begin{array}{l}\mathrm{NaCl} \\
150 \mathrm{~mm}\end{array}$} & \\
\hline & & \multicolumn{2}{|l|}{$42 \pm 0.2$} & \multicolumn{2}{|l|}{$42 \pm 0.3$} & \multicolumn{2}{|l|}{$69 \pm 2.1$} & \\
\hline & & \multicolumn{2}{|l|}{$68 \pm 3.1$} & \multicolumn{2}{|l|}{$33 \pm 1.1$} & \multicolumn{2}{|l|}{$62 \pm 4.3$} & \\
\hline
\end{tabular}

The values represent the mean of three assays $( \pm \mathrm{SD})$; except for the Walsh inhibitor assays, which were carried out in duplicate.

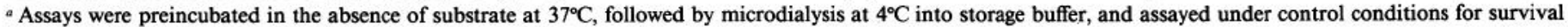
of activity: $15 \mathrm{~min}$ assay with $2 \mathrm{mM} \mathrm{Mg}^{2+}$ and $1 \mathrm{mM}$ ATP.

${ }^{b}$ Preparations of PK40: see Table 1, Method B, Step V, and Figure 5C, lane b; preparations of PK36: see Table 1, Method A, Step IV and Figure 5C, lane d.

c All values represent relative activities in percentage of the control. 
A

B

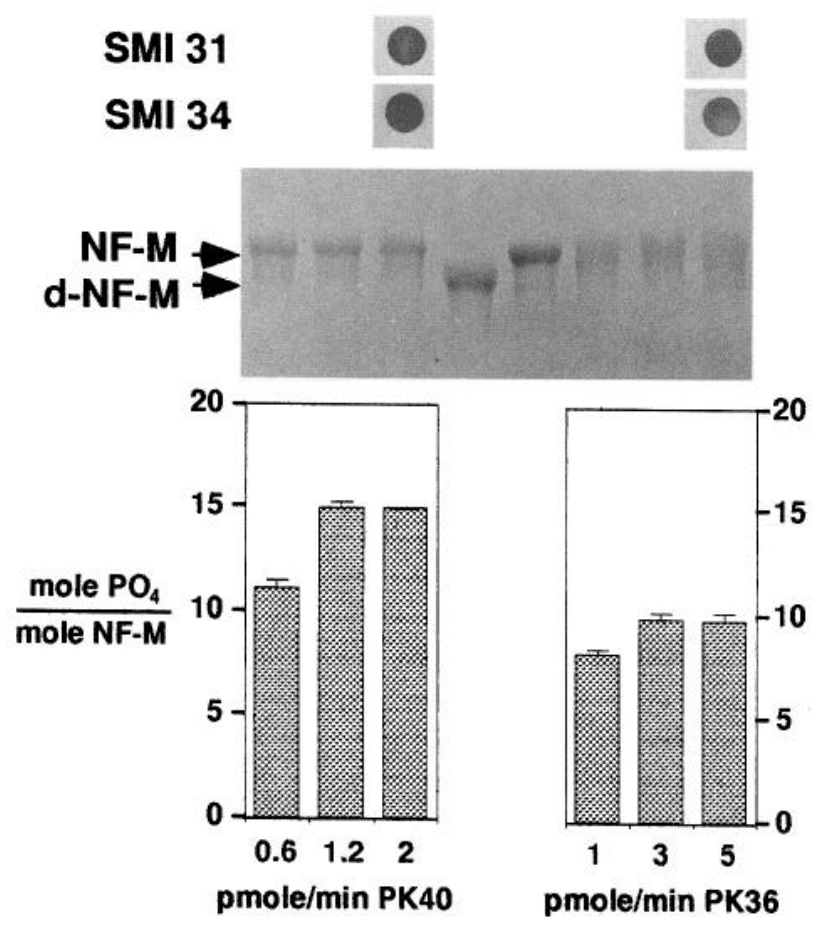

\section{SMI 31}

SMI 34

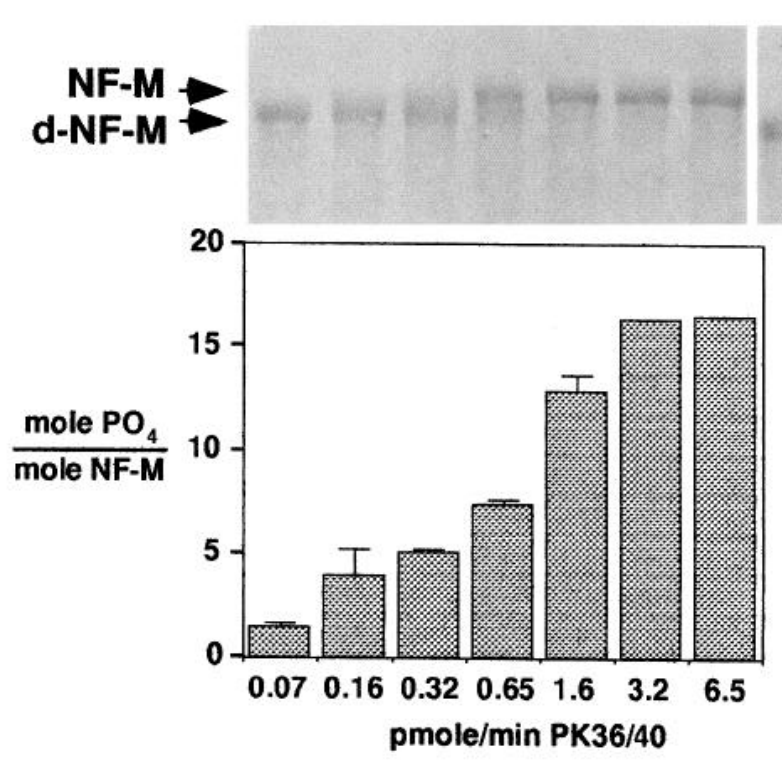

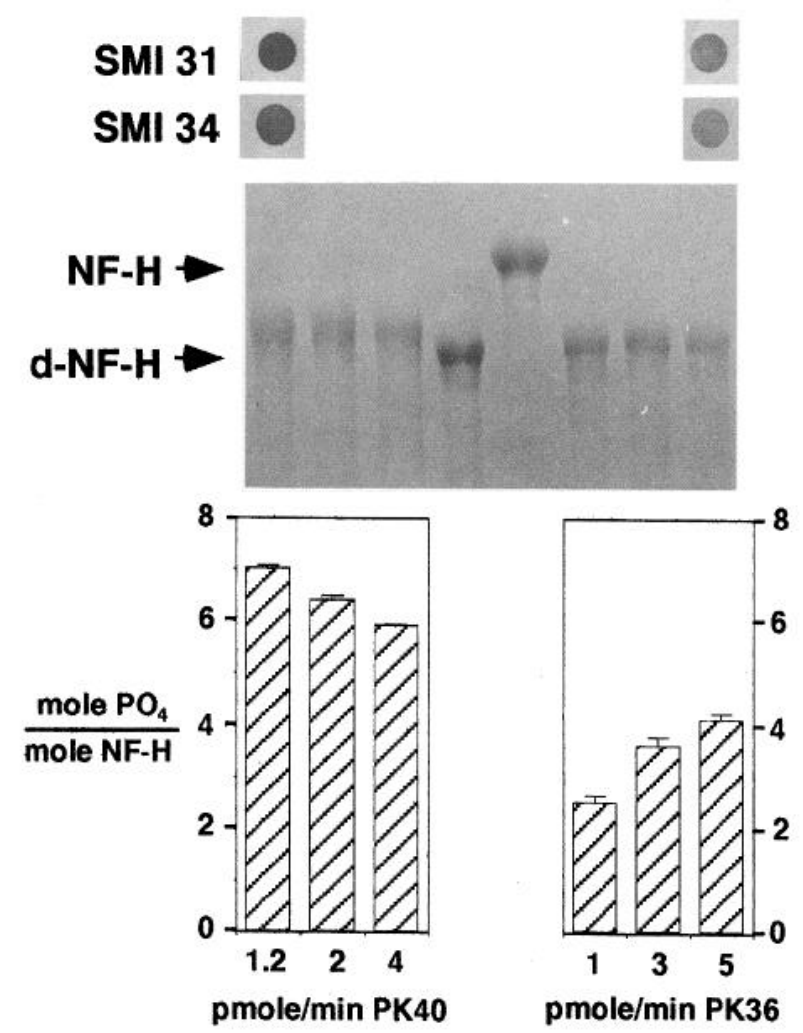

Figure 11. Saturation phosphorylation of dephosphorylated NF-M (top) and NF-H (bottom) by PK40 (A), PK36 (B), and PK36/40 (C) (as used in Fig. $5 C$, a), by increasing amounts of enzyme activity in $18 \mathrm{hr}$ assays monitored by ${ }^{32} \mathrm{P}$ incorporation, gel mobility shift on $7.5 \% \mathrm{SDS}$ polyacrylamide gels, and SMI-31/34 immunoassays. PK40 can induce a complete shift of dephosphorylated NF-M $(d-N F-M)$ but only a partial shift of NF-H; the lanes between $A$ and $B$ and the last two lanes in $C$ indicate the mobilities of the dephosphorylated and native NF subunits, respectively. Error bars are mean values $\pm \mathrm{SD}$. 


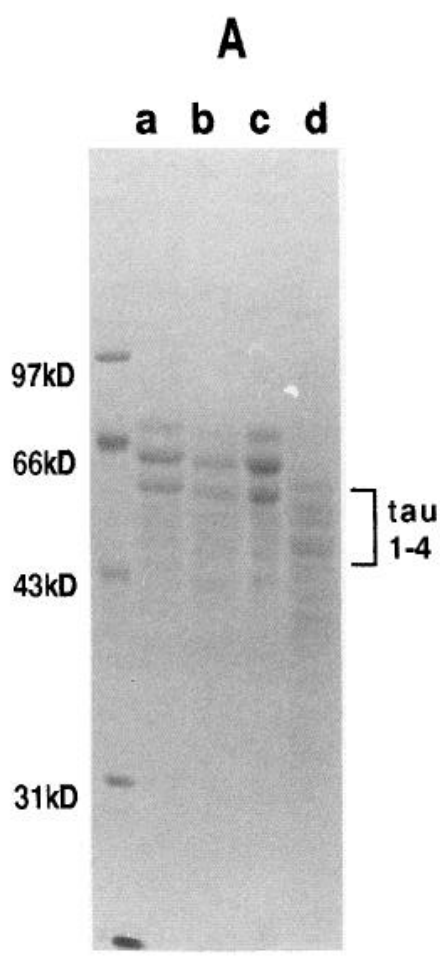

B

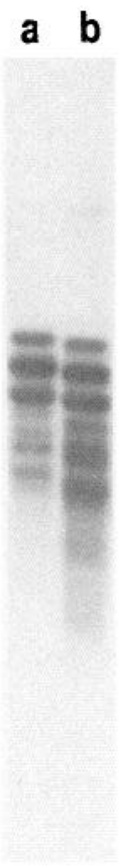



Figure 12. Saturation phosphorylation of native and dephosphorylated tau protein by PK 40 monitored by SDS-PAGE, followed by Coomassie blue staining $(A)$, autoradiography $(B)$, and Western blotting with SMI-33 (C). Dephosphorylation of native bovine tau (lanes $c$ ) resulted in four bands, tau 1-4 (lane d), of lower apparent $M_{r}$ as expected. The original $M_{r}$ could be completely restored by PK 40 phosphorylation (lane $b$ ). Saturation phosphorylation of native tau resulted in only a small additional gel shift (lane $a$ vs. $b$ and $c$ ). The fact that less than $10 \%$ of the ${ }^{32} \mathrm{P}$-labeled tau protein was recovered on the nitrocellulose blot may account for the weak staining of the blot $(C)$.

dimensional SDS-PAGE (Butler and Shelanski, 1986). The fact that we obtained fewer apparent isoforms that did not exhibit any further substantial shift on phosphorylation might be due to selective enrichment of isoforms or a higher degree of phosphorylation in our preparation. We isolated tau as a side-product in the course of the kinase purification after prolonged exposure to the crude enzymes in $\mathrm{Mg} / \mathrm{ATP}$ buffers at $4^{\circ} \mathrm{C}$.

Only the dephosphorylated tau, and not the native or the rephosphorylated protein, reacted with SMI-33 (Fig. 12C) as a probe for the unphosphorylated KSP sequence (Lee et al., 1988) that occurs twice in the sequence of all bovine tau isoforms (Himmler et al., 1989). Conversely, the SMI-34 epitope is only found in the phosphorylated or rephosphorylated tau species (data not shown). This fact together with the ability of PK40 to phosphorylate the KSP site in NF suggests that one or both of the KSP sites of tau may also be target sequences for PK40.

Similar results were obtained with a pure human tau isoform expressed in $E$. coli from the clone Htau 40 (Goedert et al., 1989). Under saturating conditions, PK40 incorporated up to 14 phosphates into the $42 \mathrm{kDa}$ tau isoform (H. Roder and E.M. Mandelkow, unpublished observations). These experiments were carried out under conditions similar to those of Figure 11. This may not be an unreasonably high number, although lower phosphate content was found in tau previously (Lindwall and Cole, 1984). The phosphate content of isolated tau may not correspond to the in vivo situation. For example, in the case of



Figure 13. Comparison of peptide maps of NF-H after protease V8 digestion by Western blotting with SMI-31 and SMI-34. Pure NF-H $(12 \mu \mathrm{g})$ was partially digested with $0.25 \mu \mathrm{g}$ of $\mathrm{V} 8$ protease in ammonium bicarbonate buffer at $\mathrm{pH} 7.8$ for $1 \mathrm{hr}$ at $37^{\circ} \mathrm{C}$. The peptide mixture was separated on a $10-20 \%$ SDS gradient gel, and Western blots were prepared.

MAP2, 8-50 mol of phosphate/molecule were found, depending upon the speed of preparation (A. Matus, personal communication). PK36 induced an incomplete mobility shift in tau protein, as in the case of NF-M.

\section{The relationship between the SMI-31 and SMI-34 epitopes}

In almost all aspects of the characterization of the kinases PK40 and PK36, the SMI-31 immunoassays closely paralleled the SMI-34 assays, indicating a close relationship. This was further substantiated by probing a peptide map of native NF-H after digestion with V8 protease with both mAbs on Western blots. The similarity of the staining patterns suggests that the two epitopes are probably not qualitatively different (Fig. 13). The two mAbs more likely require different degrees of phosphorylation for binding to MPR sites in the heavy NF subunits. The differential binding of SMI-31 and SMI-34 to NF-M at intermediate degrees of phosphorylation by PK40 (Fig. 11C) supports this notion; it seems to be the only significant difference between the two mAbs observed so far.

\section{Discussion}

\section{$P K 40$ and $P K 36$ are distinguished from other kinases}

The physiological relevance of NF and tau phosphorylation by common kinases, such as cAMP-dependent kinase (Leterrier et al., 1981) or protein kinase C (Sihag et al., 1988) remains in doubt. With a novel immunoassay, we have identified two new kinases that are capable of phosphorylating the MPR sequences of the heavy NF subunits in high stoichiometric ratios and of inducing, by phosphorylation, complete or partial shifts on SDSPAGE of apparent $M_{r}$ of dephosphorylated NF-M and NF-H and of tau proteins (as observed in vivo, Lindwall and Cole, 1984; Nixon et al., 1987; Pleasure et al., 1990). This property, together with the behavior during purification, apparent molecular mass on SDS-PAGE, the independence from common second messengers, and other enzymatic properties like sub- 
strate specificity, distinguishes PK40 and PK36 from other wellknown kinases. We suggest that they are novel enzymes by biochemical criteria. In addition to phosphorylating KSP sites, PK40 is further distinguished from the $40 \mathrm{kDa}$ catalytic subunit of protein kinase A by lack of inhibition with the Walsh inhibitor.

The PK40 and PK36 kinases were isolated as catalytic proteins. They do not appear to be closely associated with the cytoskeleton, nor do they display obvious regulatory properties such as subunit association, homomer formation, or autophosphorylation, as seen in other common kinases. However, we cannot exclude the possibility that regulatory domains were lost by proteolysis during processing or that regulatory phosphorylation had occurred during the lengthy purification in $\mathrm{Mg} / \mathrm{ATP}$ containing buffers. A dissociating subunit could have been lost during the AS fractionation but probably not afterward, since the $M_{r}$ of the kinase activities in the crude AS fraction, as determined by low-salt gel filtration, resembled closely the apparent $M_{r}$ of the purified enzymes.

The apparent $K_{m}$ values for ATP of PK40 $(\sim 100 \mu \mathrm{M})$ and PK36 $(\sim 50 \mu \mathrm{M})$ are significantly higher than for most other kinases (2-20 $\mu \mathrm{M})$ and reflect a requirement for relatively high ATP concentrations. Interestingly, both kinases, but especially PK40, are strongly inhibited when ATP is in relatively small excess over $\mathrm{Mg}^{2+}$. A similar regulatory phenomenon is known for phosphofructokinase, which is much more strongly inhibited by free ATP in the low-millimolar range than by the Mg-ATP complex (Lowry and Passonneau, 1966). A physiological consequence of this behavior is the "Pasteur effect"-a drastic increase of 1,6-fructose-bisphosphate levels under hypoxic conditions, for cxample, in stroke (Lowry and Passonncau, 1962), due to release of phosphofructokinase inhibition with decreasing ATP concentration.

While PK40 and PK36 share some properties, PK36 does not show such a clear preference for dephosphorylated NF-M as PK40 and has only a marginal specificity for NF-H, supporting an in vivo relevance in NF phosphorylation more for PK40 than PK36. The Walsh inhibitor, which does not affect PK40, lowers the activity of PK36 in a dose-dependent fashion, although only at relatively high concentrations. Thus, the active sites of the two kinases may be quite unrelated to each other and to the catalytic site of protein kinase $A$.

\section{Significance of NF phosphorylation}

Little information is available concerning stoichiometry and sites of phosphorylation for other kinases phosphorylating NF subunits. Protein kinase $\mathrm{C}$ has been shown to phosphorylate several sites in NF, among them a site in NF-L that is phosphorylated in vivo (Sihag et al., 1988), but the specificity of this kinase for NF protein was not very high. In NFs prepared without solubilization in urea, only NF-M of the three subunits was reported to be phosphorylated by microtubule-associated kinase (Leterrier et al., 1981).

The fact that PK36 and PK40 can phosphorylate only a subset of KSP sites in NF-M and NF-H, respectively, may indicate that not all KSP sites in the heavy NF subunits are conformationally and perhaps also functionally equivalent. Likewise, the MPR sequences in NF-M and NF-H are obviously different and may serve different purposes, since PK40 apparently can saturate this site in NF-M but not NF-H and since different phosphatases have to be used for complete dephosphorylation of each isolated subunit. In this respect, it is interesting to note that the $67 \mathrm{kDa}$ NF-associated kinase isolated by Wible et al. (1989) accepts only partially phosphorylated NF-H as substrate. This suggests that NF-H may be primed by another kinase, perhaps PK40, for further phosphorylation by NF-associated kinases of the Wible type. In vivo, multiple phosphorylated NF-H variants distinguished by apparent $M_{r}$ were found to be differentially distributed along axons of retinal cell neurons, with generally increasing levels of phosphorylation toward the distal end (Lewis and Nixon, 1988). However, caution has to be exercised in the comparison of in vivo behavior of NF with results obtained in vitro with isolated NF subunits, since their substrate properties may be different from the assembled NF complex in vivo and may even depend on subtle differences in the nature of the assembly, as exemplified by our dephosphorylation studies. Different roles in the cytoskeletal network for NF-M and NF-H are suggested by ultrastructural and in vitro studies (Minami and Sakai, 1983; Hirokawa et al., 1984) where positive evidence for a cross-linking function in the NF and microtubule networks was found only for the C-terminal domain of NF-H but not NF-M. There is no clear evidence of a specific function for NF-M to date.

Our observation that dephosphorylated NF triplet in contrast to the original native triplet does not form a stable suspension in vitro (see Materials and Methods) may point to a function of NF proteins associated with NF phosphorylation, not necessarily of the MPR sequence, in stabilizing a gel formed by NF proteins, as suggested earlier (Hoffman et al., 1987).

\section{Possible pathological and cell biological significance of PK40 and PK36}

Onc of our immunoassays was designed to detect specifically a kinase that establishes the epitope of the mAb SMI-34, a marker of AD (Sternberger et al., 1985) and aging (Blanchard and Ingram, 1989) in the human brain. Our results indicate that the SMI-34 epitope is closely related to the phosphorylated MPR sequence of NF and probably to the KSP site(s) of tau rather than constituting a unique "pathological" epitope. However, at least in the case of NF-M, a relatively high saturation of the MPR sequence with phosphates seemed to be necessary for SMI34 binding. Thus, the presence of the epitope in rat brains but not normal human brains (Sternberger et al., 1985; Blanchard and Ingram, 1989) might be due to different threshold levels of phosphorylation required for SMI-34 binding that are exceeded in human brains only in a pathological condition like $\mathrm{AD}$ or in the process of aging. This hypothesis would invoke a hyperphosphorylation of cytoskeletal proteins rather than the formation of new abnormal cpitopes.

One particularly interesting mechanism involves the upregulation of PK40 (and PK36 to a lesser extent) due to degenerative or pathological metabolic insufficiency. PK40/PK36 activity, normally confined primarily to the cell processes where most of the KSP phosphorylation occurs (Sternberger and Sternberger, 1983; Lee et al., 1987), might be released from inhibition and might then spread into the perikaryon when ATP levels decrease due to age or degenerative disease (Bennett et al., 1990). Increased formation of the KSP phosphoepitopes of RT97 (Rasool and Selkoe, 1984) and of SMI-34 (Sternberger et al., 1985), as found in PHFs/tangles, would follow and lead to extensive tangle formation in neuronal cell bodies (Roher et al., 1988).

Recent reports by Blass and his colleagues (Baker et al., 1988; Blass et al., 1990) support the possibility that the regulatory properties of PK40(36) might indeed be of relevance in neu- 
rodegenerative diseases like AD. Uncoupling of oxidative phosphorylation in fibroblasts under culture conditions that favor neuronal differentiation and the consequent decrease of the ATP concentration induces the appearance of PHF and Alz-50 epitopes. In agreement with these observations and with our findings, decreased levels of ATP are to be expected in AD neurons and, perhaps to a less severe degree, in normally aged neurons. Oxidative metabolism was found to be decreased in aged ncurons as well as in fresh brain tissue of $\mathrm{AD}$ patients and was linked to ACh deficiency (Gibson and Peterson, 1981; Sims et al., 1987). Mitochondria from AD brains appear to be partially uncoupled (Sims et al., 1987). Furthermore, a selective deficiency in the respiratory enzyme cytochrome oxidase has been reported in blood platelets of AD patients (Parker et al., 1990).

The phosphorylation of tau protein by PK40 and PK36 is particularly interesting in view of the prominent involvement of tau in the formation of PHFs (Goedert et al., 1989). A possible effect of inappropriate tau(NF) protein phosphorylation in the perikaryon via the above mechanism could be interference with normal folding pathways (Urry et al., 1989) leading to extremely insoluble aggregates. Alternatively, aluminum might become chelated by phosphate groups in tangle-bearing neurons (Garruto et al., 1984) and thus cross-link hyperphosphorylated tau protein. In vitro, aluminum can precipitate phosphorylated, but not dephosphorylated, NF proteins (Nixon et al., 1990).

Several reports indicate the presence of abnormal tau-derived phosphoepitopes in PHF (Grundke-Iqbal et al., 1986; Ishiguro et al., 1988; Kondo et al., 1988). A recent study (Bancher et al., 1991) concludes that abnormal phosphorylation of tau occurs prior to its incorporation into PHF in the nerve cell body. Two classes of tau phosphorylation have been distinguished previously, according to whether the electrophoretic mobility of tau is altered (mode I) or not (mode II) (Lindwall and Cole, 1984). Immunochemical studies suggest that PHF in brains of AD patients contain only mode I phosphorylated tau proteins (Grundke-Iqbal et al., 1986; Ihara et al., 1986). Calcium/calmodulin-dependent kinase II has recently been shown to induce an apparent $M_{r}$ shift of tau of about $4 \mathrm{kDa}$ after phosphorylation of a single site (not KSP) in the C-terminal domain of tau (Baudier and Colc, 1987; Stciner et al., 1990). A tubulin-dependent kinase copurifying with microtubules also phosphorylates tau in mode I and forms a PHF-specific phosphoepitope (Ishiguro et al., 1988). PK40 and perhaps PK36 deserve equal attention as potential tau kinases since both perform mode I phosphorylation on tau and are capable of forming the tangle/PHF-associated epitopes of the mAbs SMI-34 and RT97.

Of particular interest is the recent demonstration that a form of tau can be extracted from PHFs that retains the ability to form PHF-like structures and differs from normal human tau only by phosphorylation (Lee et al., 1991). In the abnormal form, the KSP sites are phosphorylated, as suggested earlier by Rasool and Selkoe (1984). The isoform pattern of this human isolate and the magnitude of the gel shift on a $10 \%$ SDS polyacrilamide gel are very similar to changes that our PK 40 induced with our dephosphorylated bovine tau preparations.

The phosphorylation of the KSP sites in the heavy NF subunits and in tau protein by a single kinase and the ability of PK40 to shift completely the apparent $M_{r}$ of both NF-M and tau on SDS-PAGE to the values found for the proteins, as isolated by us, support the notion that NF-M and tau may share a common epitope that may be of significance for determining the conformation of these proteins. It is also striking that PK36 can induce only a partial shift in both NF-M and tau. Perhaps the phosphorylation of tau and NF-M, and to a lesser degree of $\mathrm{NF}-\mathrm{H}$, serves a general common purpose in the cell biology of neurons, and perhaps the KSP sites together with an as yet unspecified sequence or conformation environment label both proteins as substrates for a kinase associated with this purpose.

A more complete analysis of the phosphorylation sites of cytoskeletal proteins and of the distribution and functional properties of the relevant kinases is required to substantiate the above hypotheses. The identification of PK40 and PK 36 provides new tools to address the questions about the normal and pathological significance of the phosphorylation of cytoskeletal proteins.

\section{References}

Baker AC, Ko L-W, Blass JP (1988) Induction of "Alzheimer" antigens in cells from normal subjects by the mitochondrial uncoupler CCCP. Soc Neurosci Abstr 14:437.12.

Bancher C, Grundke-Iqbal I, Iqbal K, Fried VA, Smith IIT, Wisniewski HM (1991) Abnormal phosphorylation of tau precedes ubiquitination in neurofibrillary pathology of Alzheimer's disease. Brain Res 539:11-18.

Baudier J, Cole RD (1987) Phosphorylation of tau proteins to a state like that in Alzheimer's brain is catalyzed by a calcium/calmodulindependent kinase and modulated by phospholipids. J Biol Chem 262 : 17577-17583.

Bennett MC, Diamond DM, Stryker SL, Parks JK, Parker WP (1990) Cytochrome oxidase inhibition impairs learning and hippocampal plasticity: implications for Alzheimer's disease. Soc Neurosci Abstr 16:555.6.

Blanchard BJ, Ingram VM (1989) Age-related neurofilament phosphorylation in normal human brains. Neurobiol Aging 10:253-258.

Blass JP, Baker AC, Ko L-W, Black RS (1990) Induction of Alzheimer antigens by an uncoupler of oxidative phosphorylation. Arch Neurol 47:864-869.

Butler M, Shelanski ML (1986) Microheterogeneity of microtubuleassociated tau protein is due to differences in phosphorylation. $\mathrm{J}$ Neurochem 47:1517-1522.

Carden MJ, Schlaepfer WW, Lee VM-Y (1985) The structure, biochemical properties, and immunogenicity of neurofilament peripheral regions are determined by phosphorylation state. J Biol Chem 260 9805-9817.

Dixon M, Webb EC (1979) The enzymes, pp 60-62. New York: Academic.

Friedrich TD, Ingram VM (1989) Identification of a novel casein kinase activity in HeLa cell nuclei. Biochim Biophys Acta 992:4148.

Garruto RM, Fukatsu R, Yanagihara R, Gajdusek DC, Hook G, Fiori CE (1984) Imaging of calcium and aluminum in neurofibrillary tangle-bearing neurons in Parkinsonism-dementia of Guam. Proc Natl Acad Sci USA 81:1875-1879.

Gibson GE, Peterson C (1981) Aging decreases oxidative metabolism and the release and synthesis of acetylcholine. J Neurochem 37:978984.

Goedert M, Spillantini MG, Jakes R, Rutherford D, Crowther RA (1989) Multiple isoforms of human microtubule-associated protein tau: sequences and localization in neurofibrillary tangles of $\mathrm{Al}$ zheimer's disease. Neuron 3:519-526.

Grundke-Iqbal I, Iqbal K, Tung Y-C, Quinlan M, Wisniewski HM, Binder LI (1986) Abnormal phosphorylation of the microtubuleassociated protein $t$ (tau) in Alzheimer cytoskeletal pathology. Proc Natl Acad Sci USA 83:4913-4917.

Hagestedt T, Lichtenberg B, Wille H, Mandelkow E-M, Mandelkow E (1989) Tau protein becomes long and stiff upon phosphorylation: correlation between paracrystalline structure and degree of phosphorylation. J Cell Biol 109:1643-1651.

Himmler A, Drechsel D, Kirschner MW, Martin DW (1989) Tau consists of a set of proteins with repeated C-terminal microtubulebinding domains and variable N-terminal domains. Mol Cell Biol 9: $1381-1388$.

Hirokawa N, Glicksman MA, Willard MB (1984) Organization of 
mammalian neurofilament polypeptides within the neuronal cytoskeleton. J Cell Biol 98:1523-1536.

Hoffman PN, Cleveland DW, Griffin JW, Lander PW, Cowan NJ, Price DL (1987) Neurofilament gene expression: a major determinant of axonal caliber. Proc Natl Acad Sci USA 84:3472-3476.

Ihara Y, Nukina N, Miura R, Ogawara M (1986) Phosphorylated tau protein is integrated into paired helical filaments in Alzheimer's disease. J Biochem (Tokyo) 99:1807-1810.

Iqbal K, Grundke-Iqbal I, Smith AJ, George L, Tung Y-C, Zaidi T (1989) Identification and localization of a tau peptide to paired helical filaments of Alzheimer disease. Proc Natl Acad Sci USA 86:56465650 .

Ishiguro K, Ihara Y, Uchida T, Imahori K (1988) A novel tubulindependent kinase forming a paired helical filament epitope on tau. $\mathrm{J}$ Biochem (Tokyo) 104:319-321.

Karlsson J-E, Rosengren LE, Haglid KG (1987) A rapid HPLC method to separate the triplet proteins of neurofilament. J Neurochem 49: $1375-1378$.

Kaufmann E, Geisler N, Weber K (1984) SDS-PAGE strongly overestimates the molecular mass of the neurofilament proteins. FEBS Lett 170:81-84.

Kondo J, Honda T, Mori H, Hamada Y, Miura R, Ogawara M, Ihara $Y$ (1988) The carboxyl third of tau is tightly bound to paired helical filaments. Neuron 1:827-834.

Kosik KS, Joachim CL, Selkoe DJ (1986) Microtubule-associated protein tau is a major antigenic component of paired helical filaments in Alzheimer disease. Proc Natl Acad Sci USA 83:4044-4048.

Laemmli UK (1970) Cleavage of structural proteins during the assembly of the head of hacteriophage T4. Nature 227:680-685.

Lee VM-Y, Carden MJ, Schlaepfer WW, Trojanowski JQ (1987) Monoclonal antibodies distinguish several differentially phosphorylated states of the two largest rat neurofilament subunits (NF-H and NF-M) and demonstrate their existence in the normal nervous system of adult rats. J Neurosci 7:3474-3488.

Lee VM-Y, Otvos L, Carden MJ, Hollosi M, Dietzschold B, Lazzarini RA (1988) Identification of the major multiphosphorylation site in mammalian neurofilaments. Proc Natl Acad Sci USA 85:1998-2002.

Lee VM-Y, Balin BJ, Otvos L, Irojanowski JQ (1991) A68: a major subunit of paired helical filaments and derivatized forms of normal tau. Science 251:675-678.

Lees JF, Shneidman PS, Skuntz SF, Carden MJ, Lazzarini RA (1988) The structure and organization of the human heavy neurofilament subunit (NF-H) and the gene encoding it. FMBO J 7:1947-1955.

Leterrier J-F, Liem RKH, Shelanski ML (1981) Preferential phosphorylation of the 150,000 molecular weight component of neurofilaments by a cyclic $\Lambda \mathrm{MP}$-dependent, microtubule associated protein kinase. J Cell Biol 90:755-760.

Lewis SE, Nixon RA (1988) Multiple phosphorylated variants of the high molecular mass subunit of neurofilaments in axons of retinal cell neurons: characterization and evidence for their differential association with stationary and moving neurofilaments. J Cell Biol 107:26892701.

Lindwall G, Cole RD (1984) Phosphorylation affects the ability of tau protein to promote microtubule assembly. J Biol Chem 259:53015305.

Lowry OH, Passonneau JV (1962) Phosphofructokinase and the Pasteur effect. Biochem Biophys Res Commun 7:10-15.

Lowry OH, Passonneau JV (1966) Kinetic evidence for multiple binding sites on phosphofructokinase. J Biol Chem 241:2268-2279.

Matus A (1988) Ncurofilament protein phosphorylation-where, when and why. Trends Neurosci 11:291-292.

Merril CR, Goldman D, Van Keuren ML (1984) Gel protein stains: silver stain. Methods Enzymol 104:441-447.

Minami Y, Sakai H (1983) Network formation by neurofilamentinduced polymerization of tubulin: $200 \mathrm{~K}$ subunit of neurofilament triplet promotes nucleation of tubulin. J Biochem (Tokyo) 94:20232033.

Minami Y, Sakai H (1985) Dephosphorylation suppresses the activity of neurofilament to promote tubulin polymerization. FEBS Lett 185 : 239-242.

Moll GW, Kaiser ET (1977) Ionic inhibition of phosphorylation of histone. J Biol Chem 252:3007-3011.

Myers MW, Lazzarini RA, Lee VM-Y, Schlaepfer WW, Nelson DL (1987) The human mid-size neurofilament subunit: a repeated protein sequence and the relationship of its gene to the intermediate filament gene family. EMBO J 6:1617-1626.
Napolitano EW, Chin SSM, Colman DR, Liem RKH (1987) Complete amino acid sequence and in vitro expression of rat NF-M, the middle molecular weight neurofilament protein. J Neurosci 7:2590-2599.

Nixon RA, Lewis SE, Marcotta CA (1987) Posttranslational modification of neurofilament proteins by phosphate during axoplasmic transport in retinal ganglion cell neurons. J Neurosci 7:1145-1158.

Nixon RA, Clarke JF, Logvinenko KB, Tan MKH, Hoult M, Grynspan $F$ (1990) Aluminum inhibits calpain-mediated proteolysis and induces human neurofilament proteins to form protease resistant high molecular weight complexes. J Neurochem 55:1950-1959.

Nukina N, Kosik KS, Selkoe DJ (1987) Recognition of Alzheimer paired helical filaments by monoclonal neurofilament antibodies is due to crossreaction with tau protein. Proc Natl Acad Sci USA 84: 3415-3419.

Pant HC, Shecket G, Gainer H, Lasek RJ (1978) Neurofilament protein is phosphorylated in the squid giant axon. J Cell Biol 78:R23R27.

Pant HC, Gallant PE, Gainer H (1986) Characterization of a cyclic nucleotide- and calcium-independent neurofilament protein kinase activity in axoplasm from the squid giant axon. J Biol Chem 261: 2968-2977.

Parker WD, Filley CM, Parks JK (1990) Cytochrome oxidase deficiency in Alzheimer's disease. Neurology 40:1302-1303.

Pleasure SJ, Selzer ME, Lee VM-Y (1989) Lamprey neurofilaments combine in one subunit the features of each mammalian NF triplet protein but are highly phosphorylated only in large axons. J Neurosci 9:698-709.

Pleasure SJ, Lee VM-Y, Nelson DL (1990) Site-specific phosphorylation of the middle molecular weight human neurofilament protein in transfected non-neuronal cells. J Neurosci 10:2428-2437.

Rasool CG, Selkoe DJ (1984) Alzheimer's disease: exposure of neurofilament immunoreactivity in SDS-insoluble paired helical filaments. Brain Res 322:194-198.

Roder HM, Ingram VM (1990) A novel neurofilament kinase. Soc Neurosci Abstr 16:387.6.

Roher AE, Palmer KC, Chau V, Ball MJ (1988) Isolation and chemical characterization of Alzheimer's disease paired helical filament cytoskeletons: differentiation from amyloid plaque core protein. J Cell Biol 107:2703-2716.

Runge MS, El-Maghrabi MR, Claus TH, Pilkis SJ, Williams RC (1981) A MAP-2-stimulated protein kinase activity associated with neurofilaments. Biochemistry 20:175-180.

Shecket G, Lasek RJ (1982) Neurofilament protein phosphorylation. J Biol Chem 257:4788-4795.

Shelanski ML, Gaskin F, Cantor CR (1973) Microtubule assembly in the absence of added nucleotides. Proc Natl $\Lambda$ cad Sci US $\Lambda$ 70:765768.

Sihag KS, Jeng AY, Nixon RA (1988) Phosphorylation of neurofilament proteins by protein kinase C. FEBS Lett 233:181-185.

Sims NR, Finegan JM, Blass JP, Bowen DM, Neary D (1987) Mitochondrial function in brain tissue in primary degenerative dementia. Brain Res 436:30-38.

Steiner B, Mandelkow E-M, Biernat J, Gustke N, Meyer HE, Schmidt B, Mieskes G, Söling HD, Drechsel D, Kirschner MW, Goedert M, Mandelkow E (1990) Phosphorylation of microtubule-associated protein tau: identification of the site for $\mathrm{Ca}^{2+}$-calmodulin dependent kinase and relationship with tau phosphorylation in Alzheimer tangles. EMBO J 9:3539-3544.

Sternberger NH, Sternberger LA (1983) Monoclonal antibodies distinguish phosphorylatcd and nonphosphorylated forms of neurofilaments in situ. Proc Natl Acad Sci USA 80:6126--6130.

Sternberger NH, Sternberger LA, Ulrich J (1985) Aberrant neurofilament phosphorylation in Alzheimer disease. Proc Natl Acad Sci USA $82: 4274-4276$

Tokutake S (1984) Complete separation of the triplet components of neurofilament by DE-52 column chromatography depends upon urea concentration. Anal Biochem 140:203-207.

Tokutake S, Hutchison SB, Pachter JS, Liem RKH (1983) A batchwise purification procedure of neurofilament proteins. Anal Biochem 135: 102-105.

Toru-Delbauffe D, Pierre M (1983) A rat brain protein kinase phosphorylating specifically neurofilaments. FEBS Lett 162:230-234.

Towbin H, Staehlin T, Gordon J (1979) Electrophoretic transfer of protcins from polyacrylamide gels to nitrocellulose sheets: procedures and some applications. Proc Natl Acad Sci USA 76:4350-4354.

Uéda K, Masliah E, Saitoh T, Bakalis SL, Scoble H, Kosik KS (1990) 
Alz-50 recognizes a phosphorylated epitope of tau protein. J Neurosci 10:3295-3304.

Urry DW, Chang DK, Prosad KU (1989) On the mechanism whereby phosphorylation modulates protein folding. Ann NY Acad Sci 568: 209-218.

Wible BA, Smith KE, Angelides KJ (1989) Resolution and purification of a neurofilament-specific kinase. Proc Natl Acad Sci USA 86:720724.

Wischik CM, Novak M, Edwards PC, Klug A, Tichelaar W, Crowther RA (1988) Structural characterization of the core of the paired helical filament of Alzheimer disease. Proc Natl Acad Sci USA 85: 4884-4888.

Wong J, Hutchison SB, Liem RKH (1984) An isoelectric variant of the 150,000-dalton neurofilament polypeptide. J Biol Chem 259: $10867-10874$.

Wood JG, Mirra SS, Pollock NJ, Binder LI (1986) Neurofibrillary tangles of Alzheimer disease share antigenic determinants with the axonal microtubule-associated protein tau. Proc Natl Acad Sci USA $83: 4040-4043$ 